\title{
O FINANCIAMENTO PARTIDÁRIO E A ESTRATÉGIA DE DOAÇÕES NA ARENA ELEITORAL
}

\author{
PARTY FINANCING AND DONATION STRATEGY IN \\ THE ELECTORAL ARENA
}

Rodrigo dos Dolandeli*

Marcela Tanaka**

\section{Resumo}

O artigo busca compreender a dimensão do financiamento partidário, enquanto variável dependente, articulando-a ao papel do partido político. Assim, questiona-se a importância do repasse partidário no processo eleitoral, especificamente para candidatos a deputado federal, como também quem seriam os maiores beneficiados, e se existe diferença entre as instâncias partidárias nacionais e subnacionais na distribuição dos recursos. Os resultados, encontrados através de dados descritivos e de análise de regressão logística binária, apontam para a importância do capital político do candidato no recebimento dos recursos partidários. Além disso, encontramos que a lógica de distribuição partidária é diferente nas esferas nacionais e subnacionais e que variáveis socioeconômicas, como gênero e profissão, também tiveram impacto em ambos os modelos.

Palavras-chave: Financiamento Partidário; Partidos Políticos; Seleção de Candidatos, Deputados Federais.

\begin{abstract}
The article aims to understand the dimension of party financing as a dependent variable, linking it to the role of the political party. Thus, the importance of party money transfers in the electoral process is questioned, specifically for candidates to the federal Congress, as well as who would be the greatest beneficiaries and whether there is a difference between national and subnational party instances in the distribution of resources. The results found through descriptive data and binary logistic regression analysis point to the importance of the candidate's political capital in receiving party resources. In addition, we found that the logic of party distribution is different at the national and subnational levels and that socioeconomic variables, such as gender and occupation, also had impact in both models.
\end{abstract}

Keywords: Party Financing; Political Parties; Selection of Candidates; Federal Congressmen.

\footnotetext{
* Doutor em Ciência Política pela Universidade Estadual de Campinas (Unicamp/Brasil). Professor e pesquisador da Universidade Federal do Pará (UFPA/Brasil). E-mail: dolandeli@gmail.com.

** Doutoranda e mestre em Ciência Política pelo Programa de Pós-Graduação em Ciência Política (IFCH/Unicamp/Brasil). E-mail: marcela.tanaka@hotmail.com.
} 


\section{Introdução}

Em setembro de 2015, o Supremo Tribunal Federal (STF) decidiu pela inconstitucionalidade das doações empresariais eliminando a principal fonte de recursos aos candidatos e partidos nas eleições. ${ }^{1} \mathrm{O}$ impacto desta medida vem sendo observado desde as campanhas municipais de 2016, sobretudo, o aumento do dinheiro público nas disputas eleitorais. $\mathrm{O}$ artigo, entretanto, não pretende se ater ao debate sobre o financiamento público, mas sim analisar o comportamento de seu principal operador: os partidos políticos. Buscamos, neste sentido, compreender os padrões de financiamento partidário nas eleições para a Câmara dos Deputados, explorando a lógica distributiva das legendas, bem como os seus determinantes.

Nesta tarefa, dialogamos com duas grandes áreas da literatura. A primeira diz respeito às dinâmicas próprias da organização partidária, da profissionalização da carreira política, dos processos de recrutamento e de seleção de candidatos. A segunda área é concernente ao debate acerca do financiamento eleitoral, seus padrões e efeitos no sistema político. São duas perspectivas teóricas, que trabalhadas articuladamente, dão conta de analisar não apenas a esfera eleitoral do legislativo nacional, mas igualmente a dinâmica interna das agremiações. Esta reflexão, a nosso ver, torna-se fundamental para a observação de como se opera o dinheiro na política.

O objetivo do artigo é discutir o peso dos repasses partidários, ainda em um contexto no qual o financiamento empresarial era dominante, considerando os seus maiores beneficiários e a divisão de tarefas entre instâncias partidárias (nacionais e subnacionais) na lógica distributiva destes recursos.

A pesquisa se delimitou ao financiamento de campanha dos candidatos a deputado federal nas eleições de 2014, em cinco estados: São Paulo, Rio de Janeiro, Santa Catarina, Piauí e Rondônia. Selecionamos estes casos justamente por possibilitarem a comparação entre distritos eleitorais que possuem elevadas, médias e pequenas magnitudes. Além disso, os estados apresentam cenários políticos diversos quanto à força política dos principais partidos do país, enriquecendo a nossa análise. $\mathrm{O}$ argumento principal do artigo

\footnotetext{
${ }^{1}$ A contribuição empresarial de campanhas foi vedada em setembro de 2015, após o julgamento da Ação Direta de Inconstitucionalidade (ADI) 4650/2011, ajuizada pela Ordem dos Advogados do Brasil (OAB).
} 
é que, por meio dos repasses partidários, a organização partidária tende a favorecer candidatos com reconhecida trajetória eleitoral e capital político.

O artigo está dividido da seguinte maneira: i) debate teórico sobre o dinheiro na política e o papel da organização partidária neste processo; ii) descrição geral do impacto do volume de recursos partidários nas eleições, comparado às demais fontes de financiamento: indivíduos e empresas; e iii) análise dos determinantes políticos e socioeconômicos dos candidatos a deputado federal, considerando tanto as instâncias nacionais, quanto as subnacionais.

\section{Debate Bibliográfico}

Com a suspensão das doações empresariais, o financiamento partidário passa a ser a principal fonte de recursos dos candidatos. No entanto, esta tendência já se identificava antes mesmo da decisão do STF em 2015. A evolução dos repasses das legendas aos candidatos e a diminuição das doações empresariais diretas já eram visíveis entre as campanhas de 2006 e 2010 (SANTOS, 2014).

Considerável parcela da opinião pública interpretou este fator como um efeito de "doações ocultas": as empresas financiariam indiretamente os candidatos por meio dos partidos para burlar a transparência na prestação de contas. De maneira diversa, compreendemos neste artigo que esse procedimento, na realidade, evidenciava o protagonismo da organização partidária, que passou a gerenciar maior volume de recursos na arena eleitoral. $\mathrm{O}$ assunto ainda é pouco explorado nas pesquisas acadêmicas, predominantemente voltadas ao investimento empresarial nas campanhas. ${ }^{2}$

Cabe destacar o balanço realizado por Mancuso (2015) sobre recentes pesquisas na área, identificando três principais vertentes. A primeira trata do financiamento como uma variável explicativa do desempenho eleitoral, assim, o dinheiro é retratado como o principal determinante do voto. A segunda analisa o financiamento enquanto variável explicativa de benefícios aos doadores, neste caso, o dinheiro é visto como determinante

\footnotetext{
${ }^{2} \mathrm{O}$ empresariado, sem dúvida, foi o grande financiador eleitoral, seja de maneira direta ou indireta, seu maior destaque na literatura decorreu justamente das grandes somas de dinheiro no processo eleitoral (FIGUEIREDO FILHO, 2009; MARCELINO, 2010).
} 
do comportamento político dos atores no processo decisório, tendo em conta os ganhos obtidos pelas empresas após o investimento eleitoral. A última enfoca as contribuições financeiras enquanto variável dependente, buscando os seus determinantes, ou seja, os interesses e motivações do financiador. Esta terceira abordagem é, particularmente, a que adotamos no presente artigo, pois buscamos compreender o que leva o partido a financiar candidaturas.

Dado um novo quadro normativo, no qual as doações empresariais foram vedadas, o empoderamento financeiro dos partidos poderia ser mantido através do dinheiro público. Com base nesta conjectura, ainda mais considerando os esforços recentes do Congresso Nacional para garantir recursos do orçamento, tendo o Fundo Especial de Financiamento de Campanha (FEFC) como o produto mais exemplar desse empreitada, ${ }^{3}$ o debate acerca do financiamento público ganha ainda mais seriedade no caso brasileiro.

A literatura tende a retratar o dinheiro público no processo político como uma contribuição do Estado com a manutenção dos partidos, ponderada pela necessidade de transparência desta aplicação (RUBIO, 2005). De acordo com Van Biezen (2004), tal tendência cristalizou-se no pós-guerra, sendo um imperativo ao bom funcionamento das democracias. A utilidade pública das agremiações, apesar da sua natureza privada, é o mote da responsabilização estatal pela conservação dos partidos.

Não é pertinente ao escopo deste trabalho uma vasta discussão da bibliografia que trata da relação entre partidos e arranjos institucionais, mas trazemos algumas contribuições nesse sentido para o caso brasileiro. Dessa forma, considerando uma literatura mais pessimista, a nossa opção pelo sistema presidencialista, proporcional e de lista aberta, levaria, necessariamente, a uma baixa institucionalização dos partidos brasileiros e à ingovernabilidade (MAINWARING, 1993; AMES, 1995). Esse diagnóstico se refletiria nas organizações internas dos partidos, incrementando estímulos à personalização da disputa (MAINWARING, 2001; MAINWARING; O’DONNEL; VENEZUELA, 1992).

\footnotetext{
${ }^{3}$ O FEFC foi instituído pela Lei 13.488/2017, e já utilizado pelos partidos na campanha de 2018.
} 
$\mathrm{O}$ argumento também se estenderia à seleção de candidatos, uma das atividades centrais da prática partidária (BRAGA, 2008; FREIDENBERG; LÓPEZ, 2008). Seguindo esse raciocínio, o arranjo institucional brasileiro diminuiria a força dos líderes, a capacidade de ordenação da lista se deslocaria do partido aos eleitores, que a definiriam no momento da eleição. Os candidatos, portanto, seriam auto selecionadores e imersos em um processo amplo e aberto (SAMUELS, 1997).

Por outro lado, uma segunda corrente bastante conhecida da literatura atesta que as organizações partidárias brasileiras controlam tanto a arena legislativa (FIGUEIREDO e LIMONGI, 2001), quanto a montagem das listas de candidatos que vão às urnas (TAVARES, 1999; NICOLAU, 2006). Partindo do pressuposto de que essa lista é previamente selecionada pelos gatekeepers (GALLAGHER; MARSH, 1988) através de meios formais e informais, argumenta-se que as lideranças partidárias têm o domínio efetivo do processo (GUARNIERI, 2004). Em termos formais, os estatutos partidários variam gradativamente da inclusão à exclusão de postulantes (BRAGA, 2008; BRAGA, VEIGA; MIRÍADE, 2009). A autoridade partidária de legendas mais centralizadas se caracteriza pela maior força das lideranças nacionais, ao passo que em partidos com estrutura descentralizada, a tomada de decisão se dá praticamente na arena local.

Controlar a seleção, segundo Guarnieri (2004), importa porque garante estabilidade política da legenda, a competição intrapartidária gera menos conflitos, o que assegura a posição dirigente dos líderes. O autor segue a concepção de Rahat e Hazan (2001), entendendo que os partidos recorrem ao desempenho anterior do candidato, de forma a definir quais seriam as posições seguras na lista. Todos os pretendentes que atingissem a quantidade de votos obtidos pelo último candidato eleito no pleito anterior, seriam considerados viáveis e, portanto, teriam mais chances de passar pelo filtro dos "porteiros".

No Brasil, o selectorate, enquanto órgão selecionador de candidatos (ÁLVARES, 2007), tem em suas mãos dispositivos capazes de ordenar informalmente a lista do partido, tais como, por exemplo, critérios para a distribuição do tempo ao Horário de Propaganda Eleitoral Gratuita (HGPE) e a distribuição do Fundo Partidário (CERVI, 2011), e a partir da campanha de 2018, também o FEFC. Esses recursos aumentam as 
chances de sucesso eleitoral e, por isso, o entendimento é que a estratégia partidária de proximidade com a elite dirigente da organização não deve ser descartada pelo político com pretensões de seguir carreira (GUARNIERI, 2004). Tudo isso significa dizer que as hipóteses da existência de partidos fracos e de políticos estimulados pelo sistema a adotarem um comportamento exclusivamente individualista, não sejam assim tão sólidas (GUARNIERI, 2004).

Considerando o processo evolutivo pelo qual as organizações partidárias atravessaram ao longo dos anos, desde o partido de massas (DUVERGER, 1980) à cartelização do sistema partidário (KATZ; MAIR, 1995), é preciso destacar que recursos financeiros são retratados na produção acadêmica como elementos fundamentais da disputa interna pelo poder da organização (PANEBIANCO, 2005; SARTORI, 2005). Isto torna, a nosso ver, essencial a observação dos padrões de financiamento partidário, que podem dizer muito a respeito dos níveis de democracia interna das organizações (HAZAN, 2002).

\section{Impacto do Financiamento Partidário nas Campanhas}

Nesta seção, serão apresentados os dados discutidos na pesquisa. Dividimo-la em quatro tópicos: i) contextos políticos subnacionais; ii) fontes de financiamento político; iii) capital político dos candidatos; e iv) modelos de regressão logística do financiamento partidário nacional e subnacional.

\subsection{Contexto político estadual}

Como foi dito no início do artigo, o financiamento partidário será observado a partir de cinco conjunturas políticas diferentes, compreendendo os estados de São Paulo, Rio de Janeiro, Santa Catarina, Piauí e Rondônia. ${ }^{4}$ Os critérios para a seleção dos casos foram a magnitude eleitoral e a força política dos principais partidos nacionais. $\mathrm{O}$ contexto nos estados citados é o que segue.

\footnotetext{
${ }^{4}$ Agradecemos imensamente as contribuições nesta seção de Jeison Heiler (PUC/SC), Vitor Sandes (UFPI) e João Paulo Viana (UNIR).
} 
Primeiro, consideramos as maiores magnitudes eleitorais (São Paulo e Rio de Janeiro). O estado de São Paulo possui o maior colégio eleitoral do país, representando $22 \%$ do eleitorado nacional. A força política do PSDB se consolidou desde a eleição de Mario Covas ao governo do estado em 1994, sucedendo a hegemonia anterior do PMDB. Até 2018, quando João Dória venceu as eleições, contabilizamos mais de vinte anos do PSDB no poder. O PT tem sido o adversário mais forte, embora amargado resultados ruins desde 2016, período de intensa crise política nacional que restringiu o apoio do partido no estado.

A polarização entre PT e PSDB, ao menos até 2014, era retratada como consistente e evidenciava de certa maneira a própria estabilidade da competição nacional entre os partidos. Cenário que a literatura conceituou de "presidencialização" das campanhas, cuja dinâmica se reproduziu progressivamente nas disputas subnacionais (SANDESFREITAS, 2015).

No contexto deste estado, PT, PSDB e PMDB, em 2014, lançaram 195 candidatos e elegeram 26 das 70 cadeiras em disputa. O PT teve 67 candidatos e elegeu 10, o PSDB teve 52 e 14 eleitos, e o PMDB apresentou 76 candidaturas obtendo 2 eleitos.

O estado do Rio de Janeiro é o terceiro maior colégio eleitoral do país, representando 8,5\% do eleitorado nacional. A polarização PT-PSDB, comparativamente ao cenário paulista, influenciou precariamente a competição estadual, pois os dois partidos, embora sempre de lados opostos nas disputas, são pouco densos eleitoralmente. O melhor desempenho do PSDB ocorreu em 1994 quando Marcello Alencar foi eleito no auge da popularidade do Plano Real, aproveitando um momento político favorável que alçou o partido à Presidência da República, com a eleição de Fernando Henrique Cardoso. E o melhor desempenho do PT ocorreu na campanha seguinte, em 1998, sendo vice da chapa vencedora, quando se coligou ao PDT. Na ocasião, o governador eleito foi Anthony Garotinho e a vice foi Benedita da Silva.

Em suma, na conjuntura política carioca, o protagonismo até 2014, pertenceu ao PMDB (SANTOS e TRAVAGIN, 2015) que elegeu três governadores seguidos. Os peemedebistas receberam apoio alternado do PSDB e do PT ao longo deste período. No estado do Rio de Janeiro, PT, PSDB e PMDB, em 2014, lançaram 107 candidatos e 
elegeram 14 das 46 cadeiras em disputa para o cargo de deputado federal. O PT lançou 36 e elegeu 5, o PSDB apresentou 41 e apenas 1 eleito, e o PMDB teve 30 candidaturas e 8 eleitos.

Com respeito aos distritos de magnitude eleitoral média, selecionamos Santa Catarina. Este estado possui um colégio de aproximadamente 4,8 milhões de eleitores, representando cerca de $3,4 \%$ do eleitorado nacional.

A campanha de 2014, a exemplo do que foi visto no Rio de Janeiro, não evidenciou no estado uma polarização entre PT e PSDB. O PT lançou sucessivamente candidaturas próprias, mas nunca chegou ao segundo turno. E o PSDB sempre esteve colocado como força auxiliar de lideranças fortes no estado, até que em 2014 também apresentou um candidato próprio. Considerando a campanha de 2014, boa parcela da base partidária do PT em nível nacional, dentre eles o PMDB e o PC do $\mathrm{B}$, aderiu à candidatura de reeleição do governador Raimundo Colombo, candidato do PSD e egresso do DEM. Os petistas lançaram Cláudio Vignatti, que ficou em terceiro lugar com 15\% dos votos. Já o PSDB, que em 2002 e 2006 esteve ao lado de Luiz Henrique, governador eleito pelo PMDB nas duas ocasiões, e que em 2010 se coligou à chapa vencedora de Raimundo Colombo, mudou de estratégia apresentando Paulo Bauer, ficando em segundo lugar com cerca de $30 \%$ dos votos. Em resumo, PT e PSDB almejaram uma relevância maior no estado lançando candidaturas próprias e demarcando o campo político.

Os dados das candidaturas catarinenses em 2014, para deputado federal, mostram que PT, PSDB e PMDB apresentaram 40 nomes e elegeram 9 das 16 vagas. Separadamente, o PT lançou 17 e elegeu 2, PSDB teve 12 candidatos e 2 eleitos, e o PMDB teve 11 candidaturas e 5 eleitos. Isso mostrou o quanto estes partidos, nacionalmente mais fortes, dominaram a disputa proporcional no estado.

Por último, tratamos dos menores colégios eleitorais selecionados no artigo: Piauí e Rondônia. O primeiro representa cerca de 1,6\% do eleitorado nacional, e o segundo, $0,8 \%$.

Observando a conjuntura política destes estados, vimos que no Piauí, o PT é o partido com maior capital político. Em 2014, ele venceu a eleição no primeiro turno para 
governador com mais de $60 \%$ dos votos. Seu candidato, Wellington Dias, já havia governado o estado em outras duas oportunidades (2002 e 2006) e foi reeleito em 2018.

Neste estado, ocorreu em 1998 uma das raras alianças entre PT e PSDB para eleições majoritárias. O PSDB lançou Francisco Gerardo a governador, tendo como vice Antônio José Medeiros do PT. A chapa ficou em terceiro lugar com apenas 13\% dos votos. Desde então, o PSDB sempre apresentou candidaturas próprias, ou coligadas opostas ao PT, mas obtendo resultados eleitorais bem inferiores.

Em 2014, para deputado federal, PT, PSDB e PMDB lançaram 7 candidatos e elegeram 3 das sete cadeiras do estado. O PT apresentou 6 e elegeu 2, PSDB não concorreu ao cargo, e o PMDB teve uma candidatura apenas, que acabou por se eleger. Neves (2010), ao retratar a política subnacional, afirma que o fato de o postulante já ter ocupado cargos no Congresso Nacional é decisiva para o seu desempenho.

Gráfico 1 - Porcentagem de deputados federais eleitos por partido e por estado em 2014

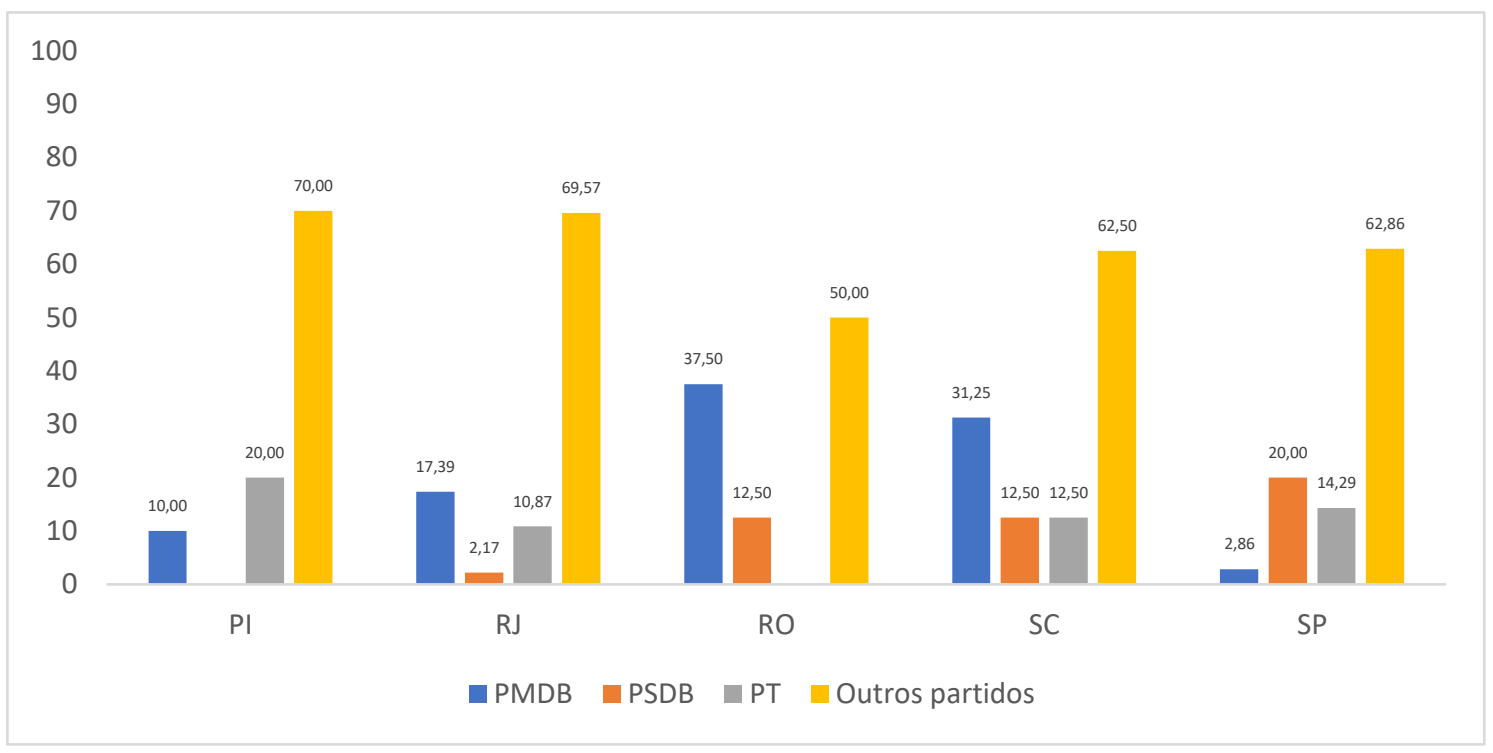

Fonte: Elaborado pelos autores com base em dados do site do TSE

Por sua vez, em Rondônia, verificamos um processo político no qual o PMDB é o partido mais competitivo. Em 2014 e 2010, ele venceu as disputas para o governo do estado. O PSDB teve um governador quando, em 2002, elegeu Ivo Cassol, que na campanha seguinte foi reeleito pelo PPS. Em 2014, o partido foi ao segundo turno, com Expedito Júnior, mas perdeu para o PMDB de Confúcio Moura. O PT, igualmente ao 
PSDB, tem lançado candidatos ao governo do estado, mas sem obter sucesso. Em 2014, apresentou o candidato Padre Ton, que ficou em quarto lugar com apenas 12,6\% dos votos.

Nessa conjuntura, para deputado federal foram lançados pelos três partidos, 25 candidaturas. Eles elegeram exatamente metade das 8 vagas. O PT lançou 10 e não elegeu nenhum, PSDB teve 4 candidatos e um eleito, e o PMDB teve 11 candidaturas e 3 eleitos.

O gráfico acima ilustra as bancadas de deputados federais dos estados selecionados, destacando o desempenho do PT, PSDB e PMDB em comparação aos demais partidos.

\subsection{Descrição do financiamento político}

A seguir, passamos a descrever o peso do financiamento político em cada estado, considerando as diferentes fontes de financiamento. ${ }^{5}$ Para este cálculo, utilizamos os dados da prestação de contas eleitorais disponibilizados no site do TSE.

O gráfico 2 nos apresenta a proporção da contribuição de cada fonte sobre a receita total obtida pelos candidatos a deputado federal nos respectivos estados selecionados. $\mathrm{Ou}$ seja, trata-se de uma observação do financiamento "direto" recebido pelos candidatos.

O gráfico aponta para o fato de que em todos os estados observados, o financiamento partidário representou a maior parte da receita arrecadada pelos candidatos. Entretanto, esta proporção varia significativamente entre os estados. No Rio de Janeiro e Santa Catarina, mais da metade (54\%) dos recursos eleitorais dos candidatos foi proveniente dos partidos. No Piauí e em São Paulo, estes valores foram 47\% e $42 \%$ respectivamente. Apenas Rondônia apresentou uma proporção abaixo dos 30\%.

\footnotetext{
${ }^{5}$ Sobre o financiamento partidário, é preciso complementar a informação dizendo que optamos por agregar as doações realizadas tanto pelos diretórios partidários, quanto pelos comitês financeiros eleitorais, em uma única variável. A justificativa é que frequentemente os comitês eleitorais redistribuem seus recursos a candidatos, tal como é feito pelos diretórios partidários. Quanto à fonte de financiamento descrita como "candidatos", referimo-nos às doações feitas por candidatos destinadas também para outras candidaturas. Faz parte da estratégia eleitoral que aspirantes a outros cargos, tais como governador e senador ou mesmo a deputado estadual (em menor frequência) façam "dobradinha" e, inclusive, financiem candidatos a deputado federal quando querem se comunicar com uma mesma parte do eleitorado. Não confundir esta fonte com "recursos próprios", que diz respeito ao autofinanciamento.
} 
Gráfico 2 - Proporção do financiamento partidário sobre a arrecadação total de candidatos a deputado federal: eleição 2014, estados SP, RJ, SC, PI e RO.

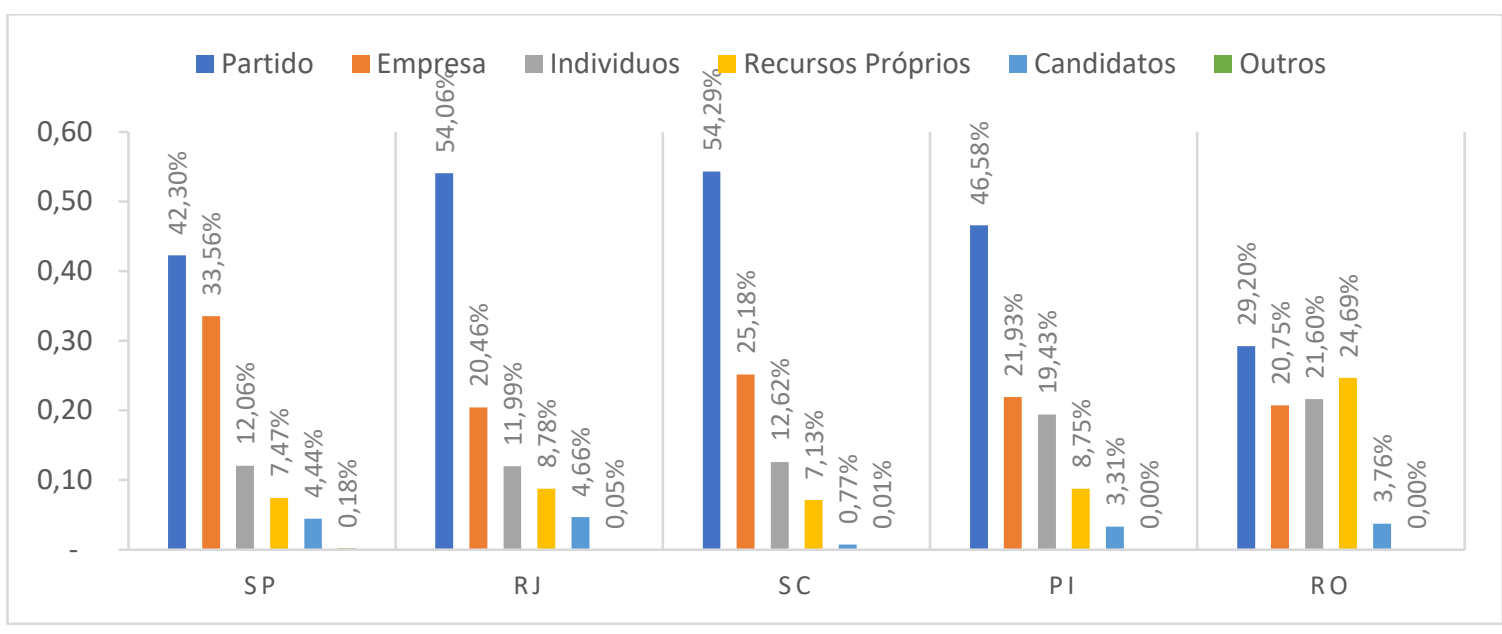

Fonte: elaborado pelos autores com base em dados do site do TSE

A segunda maior fonte de financiamento eleitoral direto a candidatos a deputado federal foi a doação empresarial. Esta proporção esteve maior em São Paulo (34\%), seguindo a casa dos 20\% nos demais estados: Santa Catarina (25\%), Piauí (22\%), Rondônia (215) e Rio de Janeiro (20\%).

Sobre as demais fontes - indivíduos, recursos próprios, candidatos e outros -, apenas no Piauí e em Rondônia, elas apresentaram um peso maior do que $15 \%$ sobre os fundos dos candidatos. Ressaltamos o peso do financiamento de indivíduos aos candidatos no Piauí (19\%) e em Rondônia (22\%). Aliás, Rondônia foi o estado onde as diferentes fontes mais se equilibraram, destacando também o emprego de recursos próprios dos candidatos que chegaram a um quarto das suas receitas. Nos outros estados, os valores de recursos próprios foram bem menores: São Paulo (7\%), Rio de Janeiro (9\%), Santa Catarina (7\%) e Piauí (9\%).

A seguir, destacamos o financiamento das principais fontes de arrecadação dos candidatos: partidos, empresas e indivíduos. Ou seja, enquanto no gráfico 2, analisamos a composição da receita eleitoral dos candidatos de todos os partidos, considerando a proporção de cada fonte, nos gráficos a seguir desagregamos os partidos e a origem da doação. Portanto, passamos a observar adiante, separadamente, o impacto da doação de partidos, empresas e indivíduos na receita dos candidatos a deputado federal do PMDB, 
PT e PSDB nos respectivos estados selecionados. Observarmos também, a média de todos os partidos.

Com respeito ao financiamento partidário, PMDB, PT e PSDB variaram bastante em relação à distribuição de seus recursos nos estados analisados. O PT, entretanto, foi o que apresentou mais de $40 \%$ em todos os estados, à exceção de Rondônia, cuja taxa ficou em 23\%. Os candidatos do PMDB receberam mais financiamento partidário no Rio de Janeiro (60\%). Em Santa Catarina (48\%), e no Piauí (46\%), estas proporções representaram quase metade dos recursos eleitorais dos candidatos, enquanto em Rondônia (26\%) e São Paulo (20\%), ficaram abaixo dos 30\%. O financiamento partidário do PSDB não teve a mesma relevância dos partidos acima mencionados. A maior proporção ocorreu no Rio de Janeiro (46\%). Em segundo lugar ficou SP com 30\%. Em Santa Catarina este valor ficou abaixo dos $20 \%$, e em Rondônia, representou apenas $12 \%$. No estado do Piauí, não verificamos lançamento de candidatos do PSD.

Gráfico 3 - Proporção do financiamento partidário do PMDB, PT e PSDB sobre a arrecadação total de seus respectivos candidatos a deputado federal: eleição 2014, estados SP, RJ, SC, PI e RO

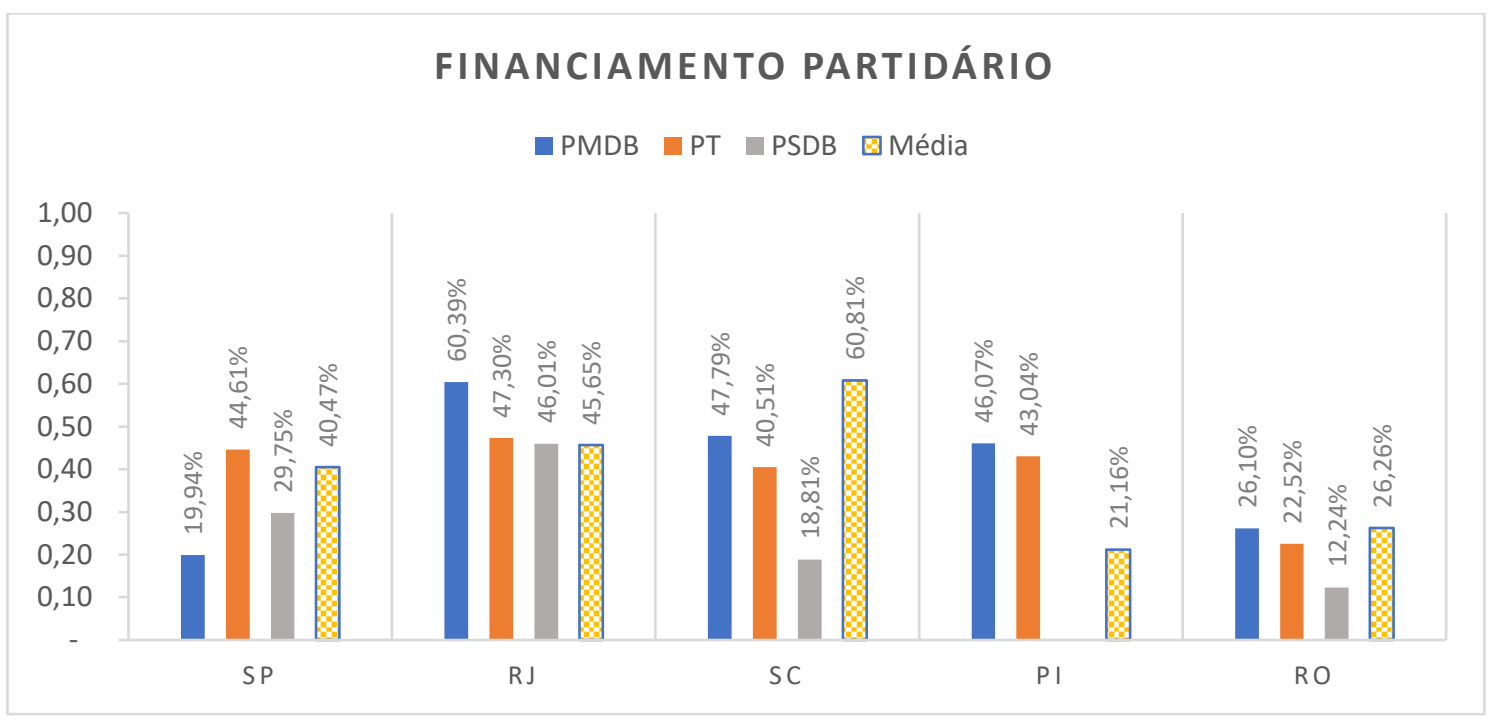

Fonte: Elaborado pelos autores com base em dados do site do TSE

Por sua vez, ao analisarmos a distribuição do financiamento empresarial, por partido e UF (gráfico 4), vimos os peessedebistas serem os mais impactados pelas doações 
de empresas. Isto ficou claro em São Paulo (50\%), em Santa Catarina (47\%) e no Rio de Janeiro (37\%).

Gráfico 4 - Proporção do financiamento empresarial sobre a arrecadação total dos candidatos a deputado federal do PMDB, PT e PSDB: Eleição 2014, estados SP, RJ, SC, PI e RO.

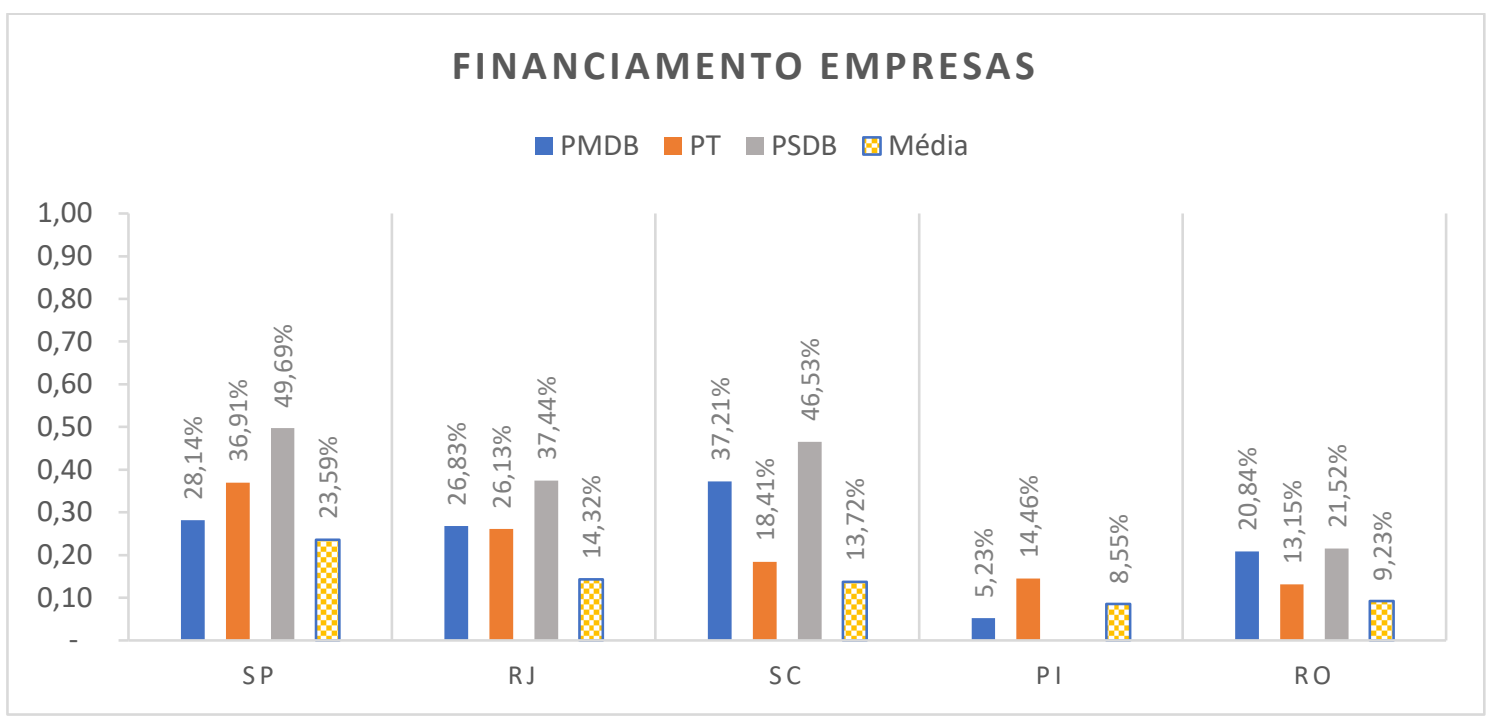

Fonte: Elaborado pelos autores com base em dados do site do TSE

O financiamento empresarial destinado ao PT também foi mais forte em SP (37\%), seguido do Rio de Janeiro (26\%) e Santa Catarina (18\%). Entretanto, para o PMDB, o maior financiamento empresarial ocorreu em Santa Catarina (37\%), sendo seguido de São Paulo (28\%) e Rio de Janeiro (27\%).

A distribuição empresarial, considerando a média de todos os partidos, é possivelmente bem associada à magnitude do distrito. Em São Paulo, o impacto destas doações na receita eleitoral dos candidatos foi de $24 \%$, e progressivamente chegou a $9 \%$ nos menores eleitorados (Piauí e Rondônia). Em comparação ao financiamento partidário (gráfico 3), esta relação não ficou clara, demonstrando que testes estatísticos de associação entre as variáveis seriam necessários para melhorar a interpretação destes dados. Mas, considerando o gráfico 5, que trata da proporção de financiamento individual, há possivelmente maior associação entre o impacto das doações de pessoas físicas na receita dos candidatos e a magnitude do distrito eleitoral. 
Gráfico 5 - Proporção do financiamento de indivíduos sobre a arrecadação total dos candidatos a deputado federal do PMDB, PT, PSDB, DEM e PSB: eleição 2014, estados SP, RJ, SC, PI e RO

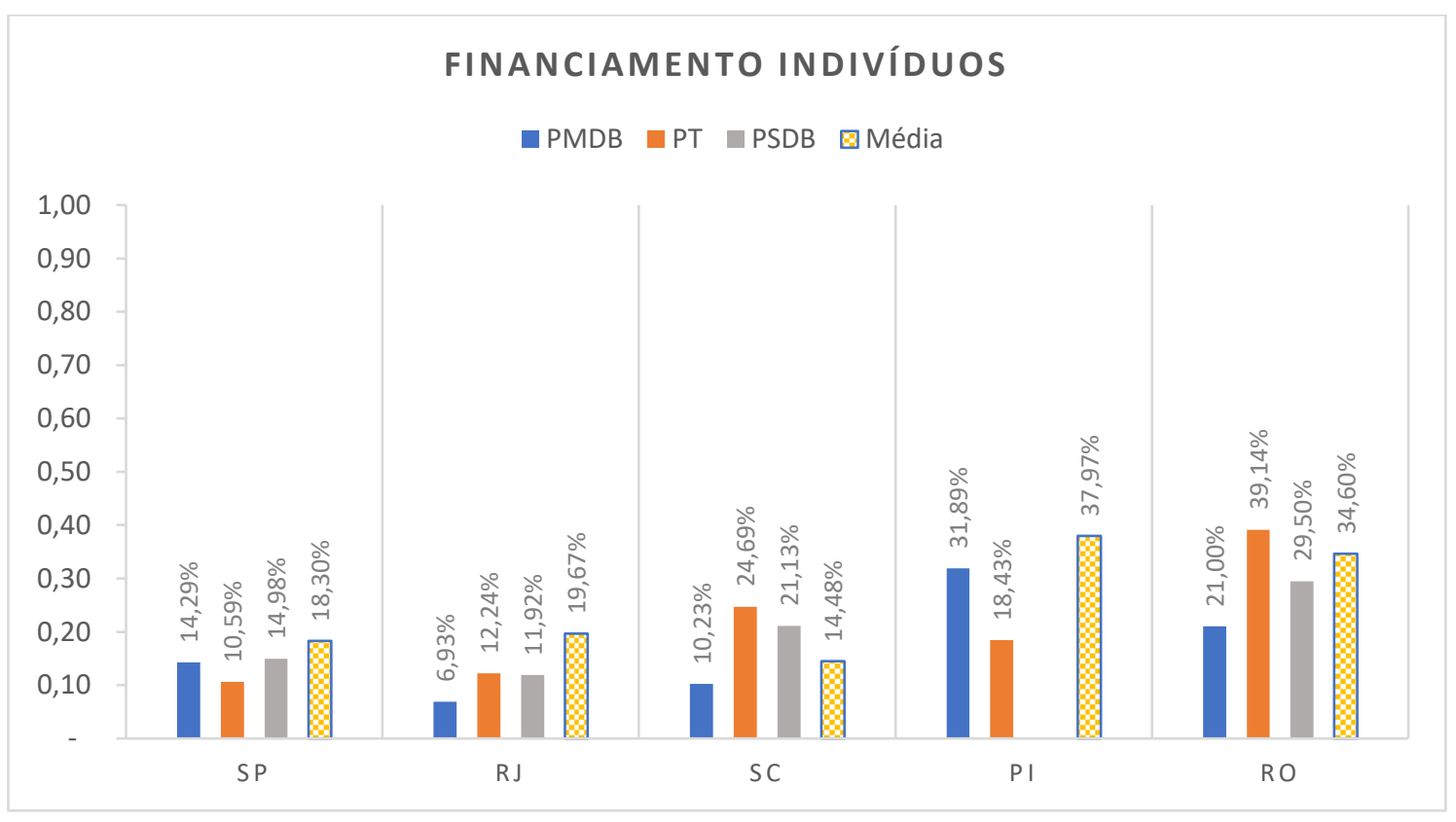

Fonte: Elaborado pelos autores com base em dados do site TSE

\subsection{Análise do capital político dos candidatos}

Nesta seção, criamos uma variável para mensurar os tipos de capital político dos candidatos, sintetizando o desempenho eleitoral anterior (2010) com o de 2014. Em primeiro lugar, calculamos o desempenho dos candidatos a deputado federal nas campanhas de 2010 e 2014. Utilizamos a fórmula de fragmentação partidária (NEP) ${ }^{6}$, identificando, portanto, candidatos que teriam sido eleitoralmente "efetivos" no estado. Assim, observamos não apenas os eleitos, mas também políticos que eventualmente assumiram o mandato parlamentar em condição de suplência. De uma forma geral, este cálculo de dispersão serve para mapearmos os políticos bem votados na campanha anterior, um fator importante na estratégia partidária (RAHAT; HAZAN, 2001). Em seguida, criamos quatro categorias, conforme descrito no quadro 1 .

\footnotetext{
${ }^{6}$ A fórmula do Número Efetivo de Partidos (NEP) foi criada por Laakso e Taagepera (1979) para analisar a fragmentação partidária $\left(1 / \sum \mathrm{pi}^{2}\right)$.
} 
Quadro 1 - Categorização variável capital político

\begin{tabular}{|c|c|c|c|c|c|}
\hline & & \multicolumn{2}{|c|}{2010} & \multicolumn{2}{|c|}{2014} \\
\hline & Capital Político & NEP & Non NEP & NEP & Non NEP \\
\hline 1 & Frequente & $\mathrm{x}$ & & $x$ & \\
\hline 2 & Novo & & $\mathrm{x}$ & $\mathrm{x}$ & \\
\hline 3 & Antigo & $\mathrm{x}$ & & & $\mathrm{x}$ \\
\hline 4 & Sem Capital & & $x$ & & $\mathrm{x}$ \\
\hline
\end{tabular}

Fonte: Elaborado pelos autores com base em dados do site do TSE

A descrição das categorias é a seguinte:

i) Capital político frequente é a característica dos candidatos competitivos tanto na campanha de 2010, quanto na de 2014. Estes políticos confirmaram a expectativa em repetir o desempenho da eleição anterior.

ii) Capital político novo é a característica dos candidatos que foram competitivos em 2014, mas que não apresentavam um sucesso eleitoral anterior.

iii) Capital político antigo é a característica dos candidatos que tiveram boa votação em 2010, mas que não a repetiram em 2014. Ou seja, neles foi depositada uma expectativa eleitoral que acabou não se confirmando.

iv) Sem capital político é a característica daqueles candidatos que não foram bem votados, considerando as duas campanhas observadas (2010 e 2014).

Os próximos gráficos $(6,7,8$ e 9) demonstram a distribuição destas categorias de capital político, somando todos as fontes de financiamento e os partidos dos estados selecionados na pesquisa. Passamos, então, a observar para onde o financiamento de partidos, empresas e indivíduos se direciona, considerando o capital político dos candidatos e os partidos. 
Gráfico 6 - Distribuição do financiamento de campanha aos candidatos a deputado federal, considerando o capital político dos candidatos do PT

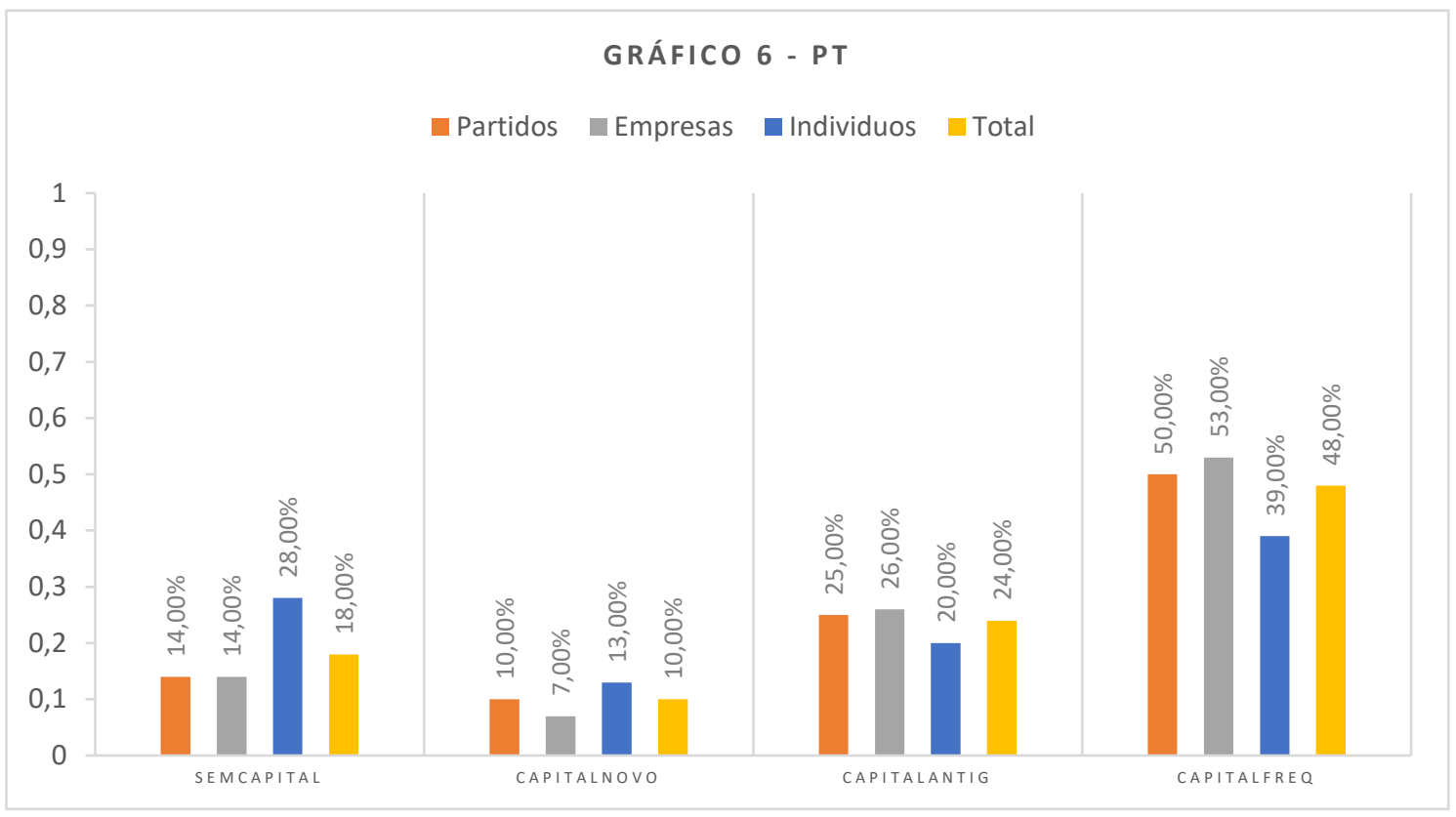

Fonte: Elaborado pelos autores com base em dados do site do TSE

Gráfico 7 - Distribuição do financiamento de campanha aos candidatos a deputado federal, considerando o capital político dos candidatos do PSDB

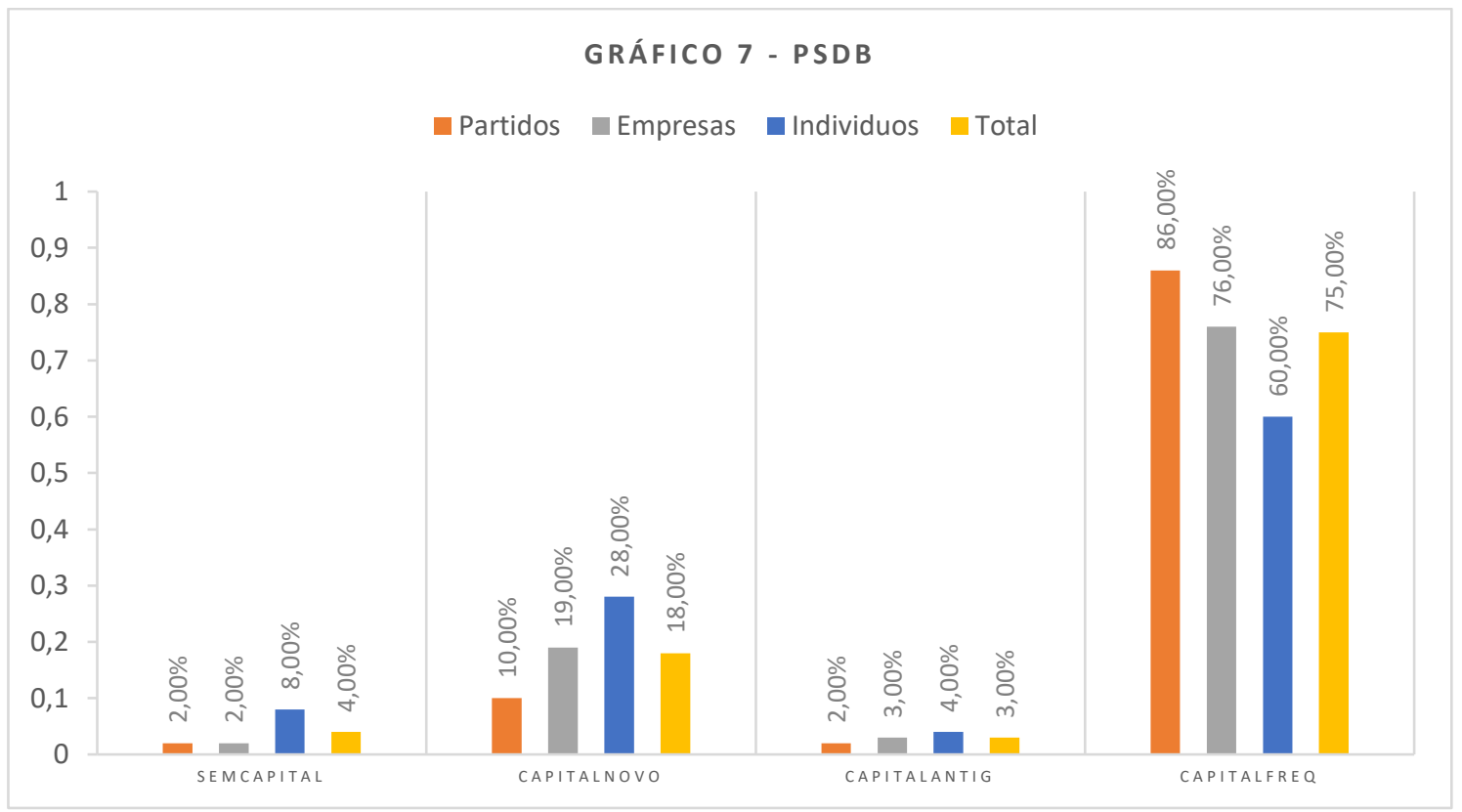

Fonte: Elaborado pelos autores com base em dados do site do TSE 
Gráfico 8 - Distribuição do financiamento de campanha aos candidatos a deputado federal, considerando o capital político dos candidatos do PMDB

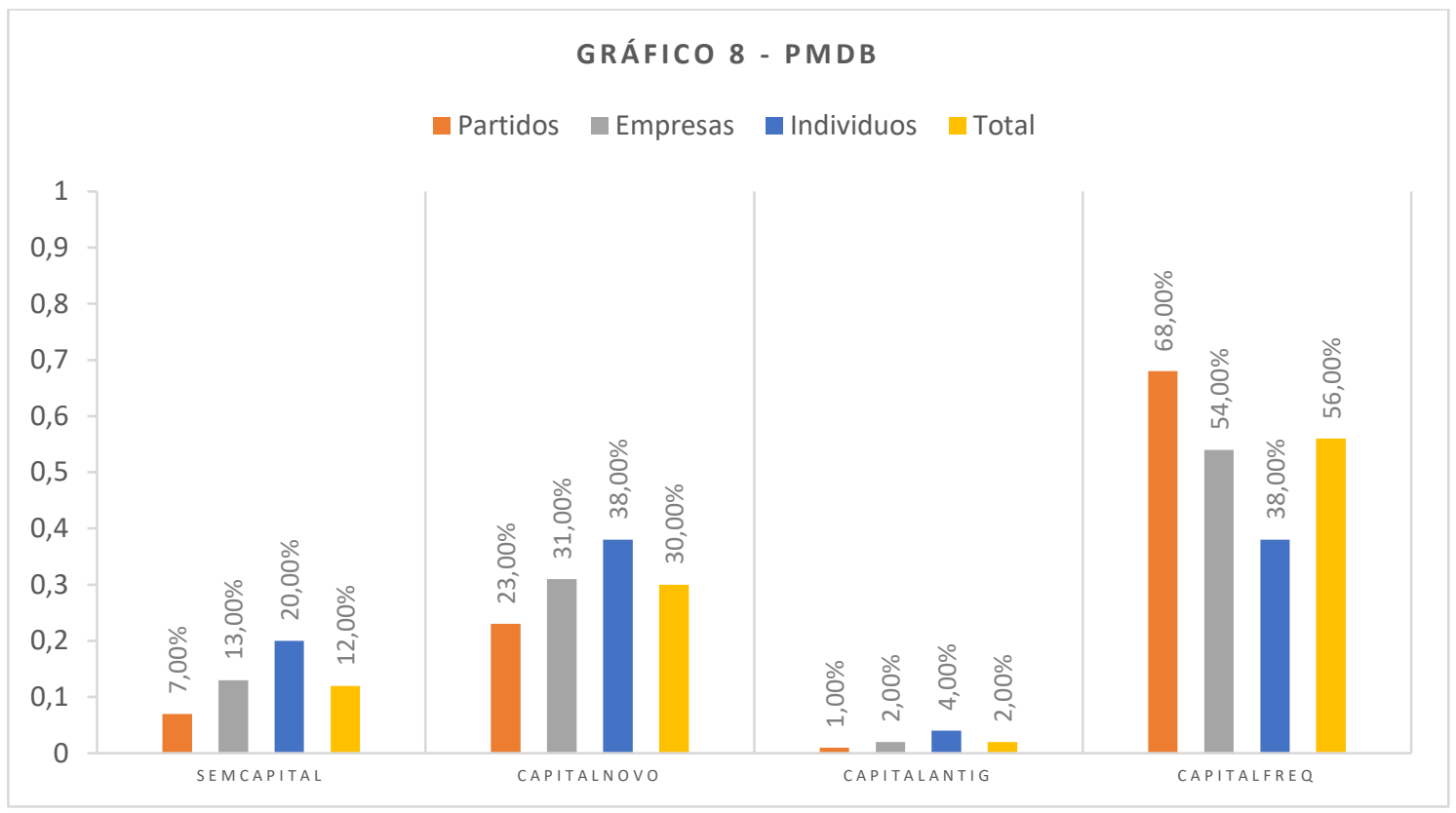

Fonte: Elaborado pelos autores com base em dados do site do TSE

Gráfico 9 - Distribuição do financiamento de campanha aos candidatos a deputado federal, considerando o capital político dos candidatos do PT, PSDB e PMDB

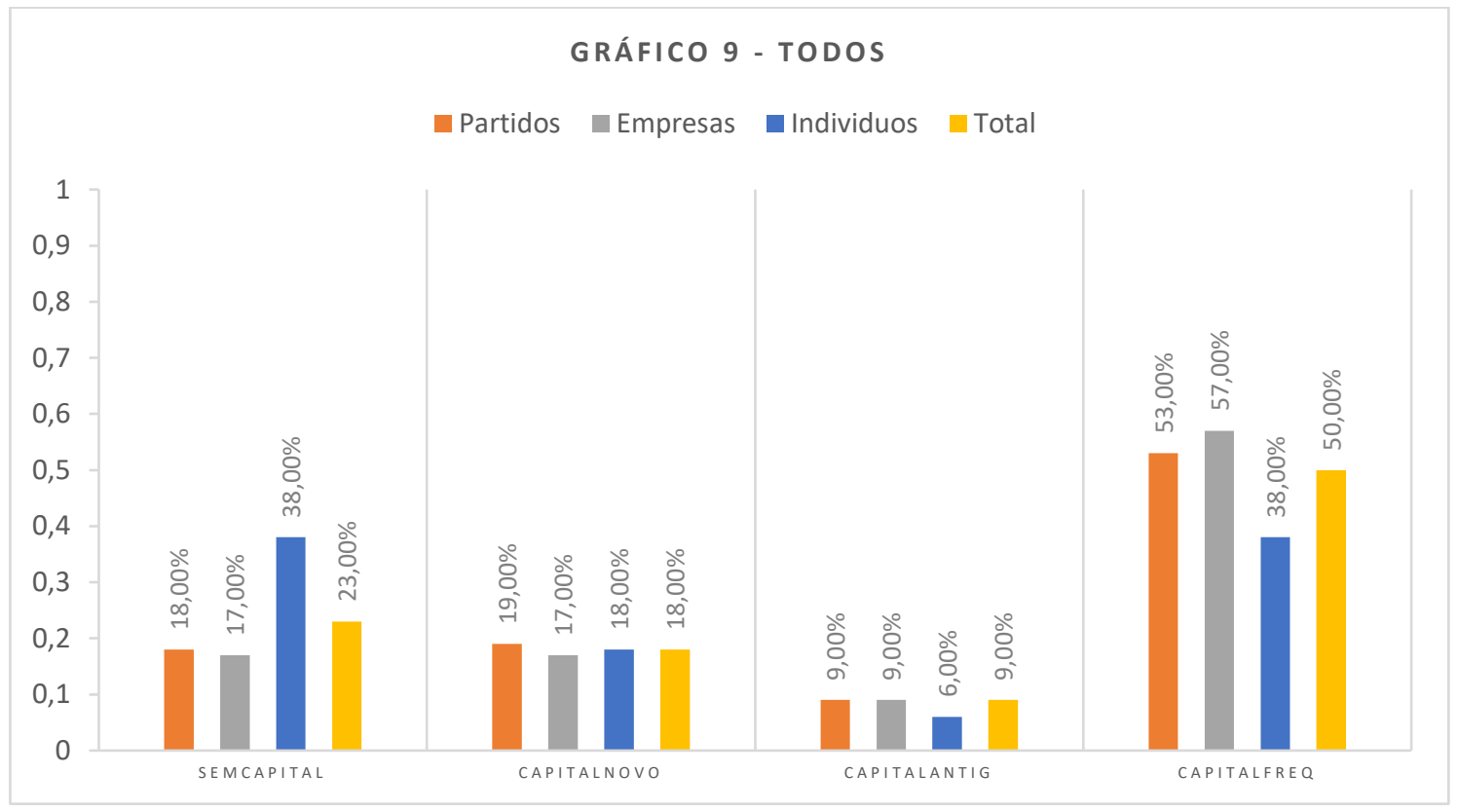

Fonte: Elaborado pelos autores com base em dados do site do TSE

Em primeiro lugar, confirmamos que os candidatos sem capital político foram aqueles que menos receberam financiamento de campanha (gráfico 9). Ao todo, somente 
23\% do dinheiro na política são destinados para estas candidaturas. Porém, se considerado apenas o financiamento de pessoas físicas, esta proporção sobe para $38 \%$. Indicando que candidatos iniciantes, ou que não tenham sido ainda bem votados anteriormente, tendem a captar maior financiamento de indivíduos. Comportamento este, bem diferente de partidos e empresas que destinaram, respectivamente, apenas $18 \%$ e $17 \%$ de seus recursos aos candidatos sem capital político.

Em segundo lugar, dentre os candidatos que possuem algum grau de capital político, verificamos que metade de todo o dinheiro investido se direcionou aos que confirmaram o bom desempenho obtido na campanha anterior ("capital político frequente"). Este direcionamento foi ainda maior considerando o financiamento empresarial (57\%) e o partidário (53\%). Enquanto o de pessoas físicas foi bem menor $(38 \%)$, significando que as empresas investem muito nos candidatos que conseguem manter seu desempenho político eleitoral.

Com respeito aos partidos, vimos que a distribuição dos recursos teve uma estrutura bastante similar. O dinheiro doado aos candidatos com capital político frequente foi maior em todas as legendas. Entretanto, se observada apenas a receita dos candidatos do PSDB (gráfico 7), o financiamento foi muito superior. As empresas destinaram $76 \%$ de seus recursos às candidaturas peessedebistas, enquanto esta proporção foi de $53 \%$ às petistas (gráfico 6), e 54\% às peemedebistas (gráfico 8). Além disso, ficou evidente que candidatos do PSDB sem capital político são bem menos financiados em comparação aos do PT e PMDB.

Outra diferença importante entre os partidos se refere aos aspirantes com "capital político antigo". Estes que não confirmaram o bom desempenho da campanha anterior, obtiveram bem mais doações quando observada apenas a receita dos candidatos do PT (gráfico 6). Enquanto a receita dos peessedebistas (gráfico 7) e peemedebistas (gráfico 8) alcançou apenas $3 \%$ e $2 \%$, respectivamente, a dos petistas chegou a $24 \%$. Indicando duas interpretações: i) a expectativa eleitoral aos candidatos do PT foi sobrevalorizada financeiramente por parte do empresariado e indivíduos; e ii) as elites partidárias petistas buscaram financiar candidatos de sua preferência, com base no desempenho anterior, sem observar o real desenvolvimento de suas campanhas durante o processo eleitoral. 
A composição da receita dos candidatos do PMDB, por sua vez, sugeriu um peso maior do capital político novo em comparação aos demais partidos. Cerca de $30 \%$ do financiamento dos peemedebistas se destinaram a estes candidatos (gráfico 8). Enquanto para petistas (gráfico 6) e peessedebistas (gráfico 7), esta proporção foi de $10 \%$ e 18\%, respectivamente. Ou seja, no caso do PMDB, os financiadores parecem estar mais atentos ao contexto eleitoral que se desenvolve no processo, mapeando novas candidaturas potenciais.

Por fim, no caso do PMDB e PSDB, as empresas destinaram menos recursos a candidatos com capital político frequente (respectivamente 54\% e 76\%), em comparação ao financiamento partidário das respectivas legendas a seus candidatos (68\% e 86\%). Este dado é importante, pois sugere que estes partidos dão maior suporte a postulantes com relevância eleitoral comprovada do que as empresas. Assim, inferimos ser possível as estruturas partidárias destas legendas estarem mais atentas a candidatos experientes eleitoralmente que apresentam bom desenvolvimento durante a campanha.

Lógica inversa ocorreu para candidatos com capital político novo do PSDB e PMDB. As empresas (PSDB: 19\% e PMDB: 31\%) e os indivíduos (PSDB: 28\% e PMDB: $38 \%$ ) buscaram financiar mais estes candidatos do que os seus partidos (PSDB: 10\% e PMDB: 23\%). Indicando que a direção do investimento empresarial direto e das pessoas físicas, de certa forma, foi em sentido à renovação dos quadros políticos. Entretanto, de forma geral, o financiamento partidário e o empresarial tendem a ter proporções semelhantes.

\subsection{Análise dos Modelos de Regressão Logística}

Nesta seção, examinamos os determinantes do financiamento partidário por meio de técnicas de regressão logística multivariada, que resultaram em dois modelos. O Modelo A diz respeito às doações partidárias nacionais, e o Modelo B, às subnacionais. Dessa forma, analisamos as razões de chance de um candidato ter obtido ou não financiamento partidário. Observamos o perfil político e socioeconômico dos candidatos, dentre os quais destacamos as variáveis gênero, profissão, capital político e outros fatores, tal como se discute na literatura produzida sobre o financiamento político. 
DOLANDELI, Rodrigo dos; TANAKA, Marcela. A. O financiamento partidário e a estratégia de doações na arena eleitoral. Caos - Revista Eletrônica de Ciências Sociais, João Pessoa, n. 23, p. 197 - 232, jul./dez. 2019. Disponível em: https://periodicos.ufpb.br/ojs2/index.php/caos/index.

Os dois modelos de regressão logística propostos se dividem em cinco partes. A primeira congrega variáveis que dizem respeito às características políticas dos candidatos. A segunda diz respeito às características socioeconômicas dos aspirantes a deputado federal. A terceira é referente ao financiamento empresarial obtido pelo postulante. A quarta trata do conjunto de variáveis das características dos partidos políticos. E a última traz uma única variável para observarmos a influência de cada caso sobre o modelo, neste sentido, trata-se dos estados selecionados (SP, RJ, SC, PI e RO). Para uma observação detalhada das variáveis e do banco de dados, consultar os Apêndices.

Abaixo, informamos a porcentagem de acerto de cada modelo. Com respeito ao modelo A, obtivemos uma porcentagem de 78,9\%, e 95,2\% no modelo B. Quanto à adequação dos modelos, encontramos níveis satisfatórios de predição e consistência, ligeiramente maiores no Modelo B, conforme podemos observar no Quadro 2. ${ }^{7}$

Quadro 2 - Porcentagem de acerto dos modelos

\begin{tabular}{|c|c|c|c|c|c|c|}
\hline \multicolumn{7}{|c|}{ Classification Table ${ }^{a}$} \\
\hline \multicolumn{7}{|c|}{ Predicted } \\
\hline & \multicolumn{3}{|c|}{ Modelo A } & \multicolumn{3}{|c|}{ Modelo B } \\
\hline & non & PartNAC & $\begin{array}{c}\text { Percentage } \\
\text { Correct }\end{array}$ & non & PartSUB & $\begin{array}{c}\text { Percentage } \\
\text { Correct }\end{array}$ \\
\hline Non & 537 & 284 & 65,4 & 154 & 85 & 64,4 \\
\hline Part & 151 & 1091 & 87,8 & 15 & 1809 & 99,2 \\
\hline $\begin{array}{c}\text { Overall } \\
\text { Percentage }\end{array}$ & & & 78,9 & & & 95,2 \\
\hline
\end{tabular}

Fonte: Elaborado pelos autores com base nos dados do site do TSE

Optamos por apresentar os resultados dos modelos em formato de Figuras de razão de chance. Em cada figura, a reta paralela ao eixo y equivale à reta de significância estatística. Cada ponto, correspondente a cada valor subescrito, se refere às razões de

\footnotetext{
${ }^{7} \mathrm{Na}$ regressão logística, para verificarmos a adequação dos modelos, utilizamos os "pseudos" $\mathrm{r}^{2}$. Quanto mais próximo de 1 os coeficientes de Cox \& Snell $\mathrm{r}^{2}$ e Nagelkerk $\mathrm{r}^{2}$ estiverem, melhor para os modelos. Verificamos os dois apresentaram consistência, sendo ligeiramente mais intenso o Modelo B (subnacional), uma vez que este apresentou o coeficiente Nagelkerke R Square de 0,554, e o Modelo A, 0,486. Sobre o parâmetro "-2 Log Likelihood", quanto menor o índice maior a sua capacidade de predição. Mais uma vez o Modelo B expressou maior capacidade preditiva.
} 
chances das variáveis (Exp B), e as retas pretas indicam o intervalo de confiança de $95 \%$.

Caso as retas não toquem a reta de significância em nenhuma de suas extremidades, isso significa que a variável está, necessariamente, acima de $\mathrm{p}<0,05$. Além disso, pontos à direita da reta de significância indicam valores positivos de Beta, e pontos à esquerda indicam valores negativos.

Figura 1 - Modelo de financiamento partidário nacional (Modelo A) ${ }^{8}$

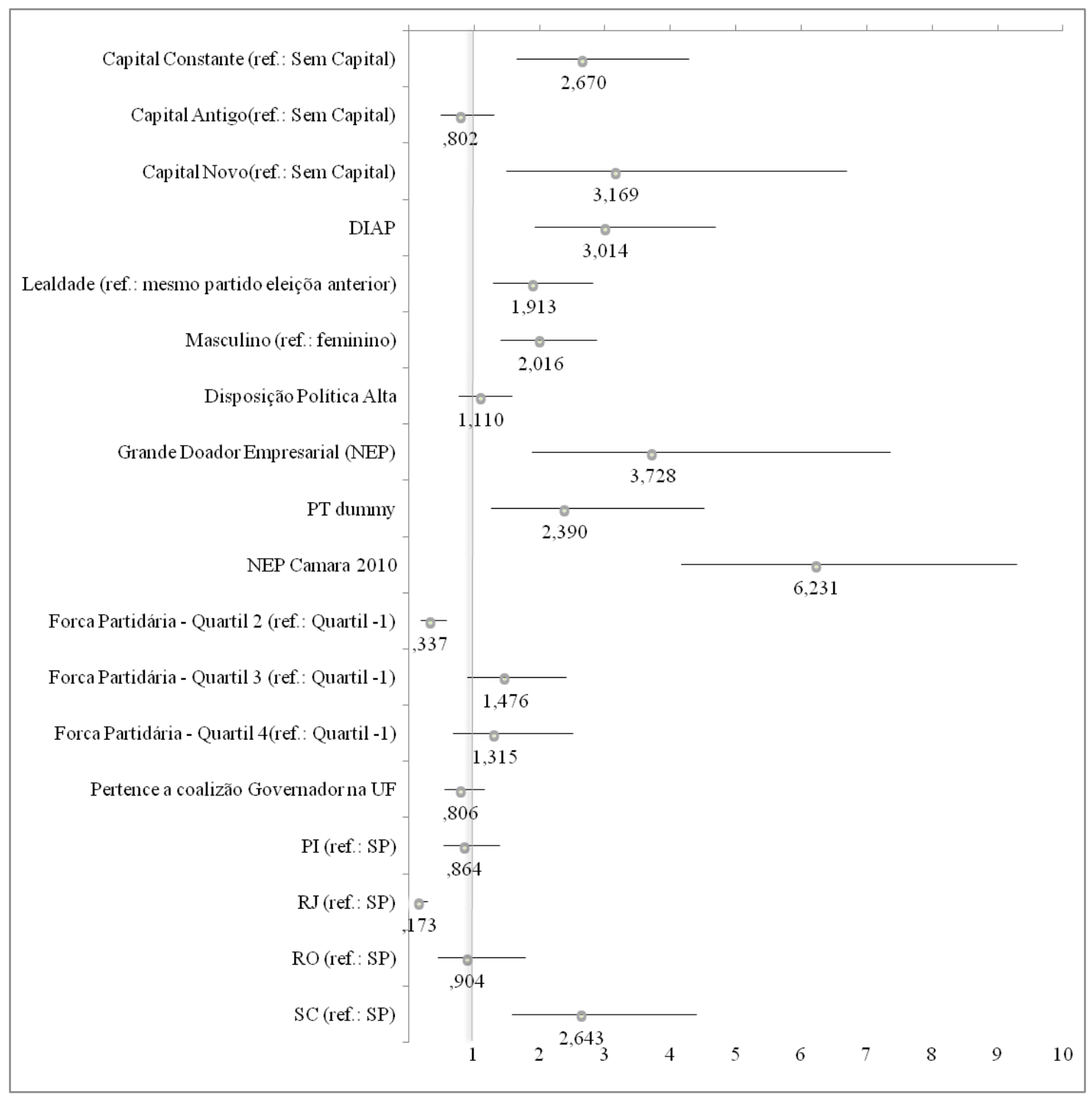

Fonte: Elaborada pelos autores com base dos dados apresentados nos gráficos e quadros anteriores

\footnotetext{
${ }^{8}$ Para mais informações, os modelos completos estão no Apêndice 6.2, ao final deste artigo.
} 
DOLANDELI, Rodrigo dos; TANAKA, Marcela. A. O financiamento partidário e a estratégia de doações na arena eleitoral. Caos - Revista Eletrônica de Ciências Sociais, João Pessoa, n. 23, p. 197 - 232, jul./dez. 2019. Disponível em: https://periodicos.ufpb.br/ojs2/index.php/caos/index.

Figura 2 - Modelo de financiamento partidário subnacional (Modelo B)

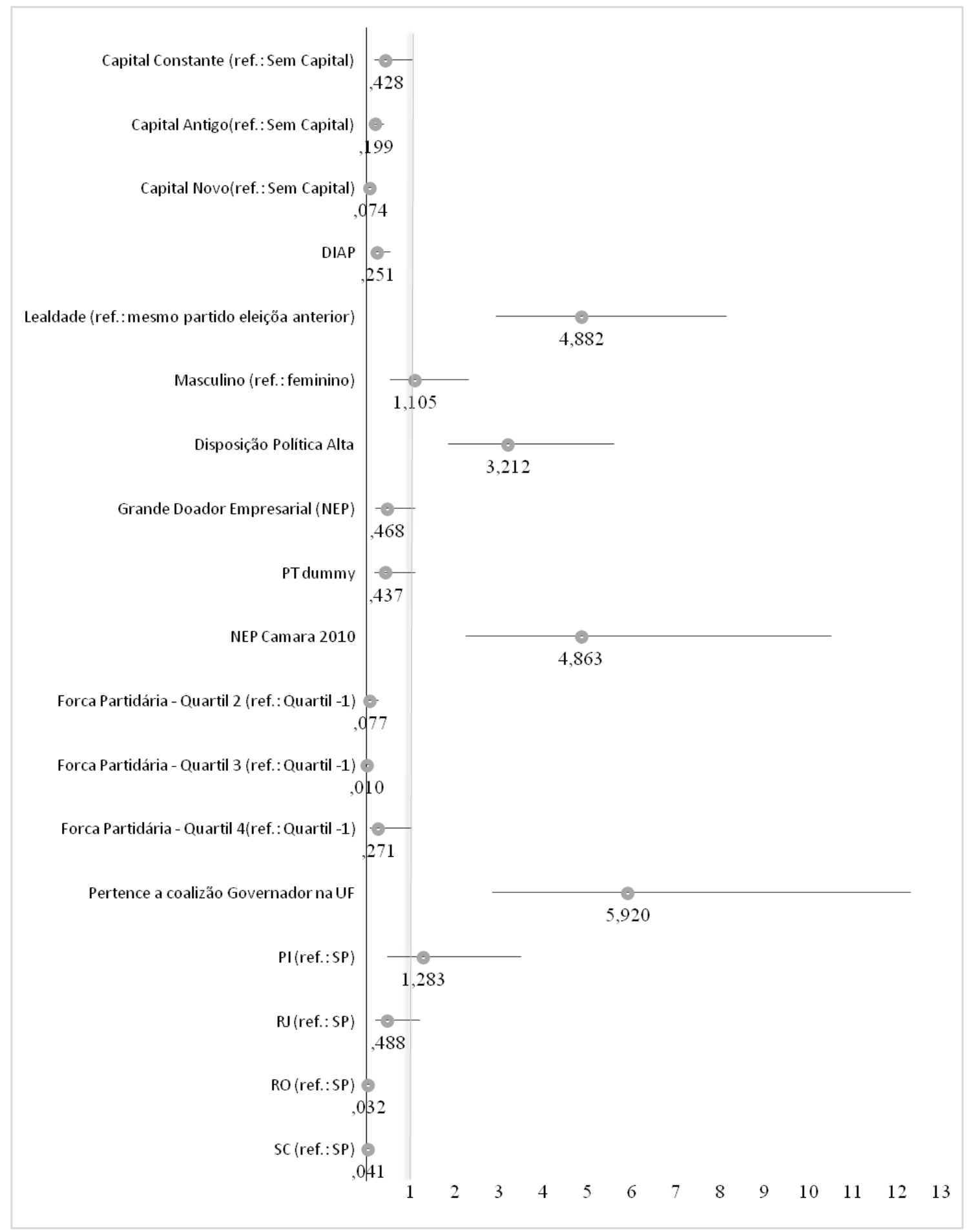

Fonte: Elaborada pelos autores com base dos dados apresentados nos gráficos e quadros anteriores

\subsubsection{Resultados}


Quanto aos resultados vamos nos basear no valor da função exponencial aplicada a cada coeficiente (Exp B), que representa a razão da chance de o candidato obter financiamento partidário, entre indivíduos da categoria em pauta, "descontando" o efeito das outras variáveis do modelo.

Acreditamos, com base nos valores apresentados pelos modelos, que conseguimos explorar as características que mais exerceram efeito sobre o financiamento partidário, seja do ponto de vista nacional, seja do subnacional. Em termos gerais, chamou a atenção o caráter de divisão de tarefas existente entre estas instâncias.

Sobre o primeiro conjunto de variáveis, os principais achados são os seguintes. O capital político do candidato é um fator significativo para que ocorra um financiamento eleitoral do diretório nacional. Os candidatos fortes eleitoralmente tiveram mais chance de financiamento de instâncias nacionais. Por sua vez, a organização partidária subnacional financiou mais os candidatos sem capital político. Assim, no âmbito estadual ficou evidente uma provisão financeira a muitos candidatos, uma vez que a maioria dos postulantes não possui experiência eleitoral. Por consequência, esta lógica acaba proporcionando maior oportunidade a novatos na política, em comparação aos diretórios nacionais.

Outra variável que reforça a divisão de tarefas "distributivas" do financiamento partidário é a relevância do ator político na arena legislativa (“DIAP”). Enquanto no Modelo A, o candidato "cabeça" do Congresso teve três vezes mais chance de ser financiado por partido nacional (em comparação aos candidatos que não obtiveram este reconhecimento do DIAP), no Modelo $\mathrm{B}$, ter tido essa relevância política, pouco influenciou. Apenas uma razão de chance de $25 \%$. Ou seja, candidatos influentes na arena legislativa nacional são muito mais agraciados financeiramente pelas estruturas partidárias nacionais do que pelos diretórios estaduais.

Outro ponto importante de ser observado é a lealdade partidária. Para a organização nacional, foi importante o candidato permanecer no partido entre uma campanha e outra (2010 e 2014). Porém, este efeito foi bem maior na esfera subnacional. No modelo B, o candidato ter permanecido no partido, elevou em 4,8 vezes a sua 
probabilidade de obter investimento partidário estadual. No modelo A, a razão de chance foi de $1,9 \%$.

Com respeito ao segundo conjunto de variáveis, referente às características socioeconômicas dos candidatos, também obtivemos informações importantes. Por exemplo, os homens tiveram duas vezes mais chance de financiamento nacional em comparação às mulheres. Já no âmbito subnacional, não houve coeficiente estatisticamente significante. O trabalho de Sacchet e Speck (2012) argumenta que as mulheres foram sistematicamente menos financiadas em 2006 e 2010. Aqui nós mostramos que para 2014, esta dinâmica também se reproduziu entre as instâncias partidárias.

No que tange à ocupação profissional, aquelas com maior disposição para a política exerceram no candidato um efeito positivo em nível subnacional. No Modelo B, houve 3,2 mais chances de profissionais liberais e servidores públicos terem sido financiados por partidos. Entretanto, no Modelo A, não houve significância estatística para esta variável.

As duas últimas variáveis analisadas demarcam diferenças importantes entre os candidatos. No Modelo A, ficou acentuado o desequilíbrio político a favor dos homens, indicando que as mulheres obtêm menos prestígio das elites partidárias nacionais. No Modelo B, ficou claro que o tipo de experiência profissional atrai a atenção da máquina local do partido.

O terceiro conjunto de variáveis, na verdade, diz respeito apenas ao financiamento empresarial obtido pelos candidatos. O partido nacional investiu mais em aspirantes, que também foram financiados por grandes doadores empresariais. Isto indica que, ao candidato, ser estratégico nacionalmente para a sua organização partidária atrai, a atenção dos grandes doadores de campanha em 3,7 vezes mais, comparativamente aos demais candidatos. Entretanto, esta variável não teve significância estatística no Modelo B.

O quarto conjunto de variáveis diz respeito às características do partido político. Aqui fica evidente também a divisão no direcionamento dos recursos. Por exemplo, ter pertencido a agremiações que mais elegeram deputados federais no estado, considerando a campanha anterior, proporcionou maior chance de o candidato receber financiamento 
nacional. Neste caso, referimo-nos ao quartil 3 da variável "força partidária", que é superior ao quartil de referência no qual se encontram as legendas com menos deputados federais eleitos no estado. Entretanto, para os partidos estaduais, o fato de o partido ter elegido mais deputados pouco impactou.

Por sua vez, este sinal se inverte quando consideramos os partidos que integraram a coalizão do governador ("Governismo"). Os diretórios nacionais pouco financiaram candidatos, dada a coalizão estadual de seu partido. Porém, pertencer a um partido governista elevou em 7,1 vezes a chance de o candidato obter financiamento de diretórios estaduais. Em resumo, em nível nacional, pouco importa investir em candidatos de partidos com base na coalizão estadual, mas sim em candidatos de partidos eleitoralmente fortes no estado.

Esta observação faz ainda mais sentido quando vemos que candidatos de partidos fortes nacionalmente ("NEP") tiveram 5,4 vezes mais chances de receber financiamentos dos diretórios nacionais. Em nível estadual, este coeficiente caiu para 3,049, porém se manteve elevado. Isto significa que os partidos fortes no congresso conseguem financiar de maneira relevante seus candidatos nos estados.

Considerando os casos observados, verificamos também uma diferença importante quanto às legendas. Os candidatos do PT, considerado um dos partidos mais organizados nacionalmente, tiveram maior probabilidade de arrecadarem recursos de diretórios nacionais em comparação aos demais partidos. Porém, no Modelo B, a razão de chance de petistas obterem financiamento partidário foi de apenas $31 \%$. Indicando também que o tipo de organização partidária, quanto à centralização de decisões estratégicas no processo eleitoral, influencia na alocação de recursos eleitorais.

Por último, a análise do ambiente eleitoral, no caso dos distritos selecionados, serviu-nos para comparar o peso do financiamento partidário nacional e subnacional.

Assim, tomando o estado de São Paulo como a referência, os candidatos a deputado federal de Santa Catarina tiveram 4,1 mais chances de receber financiamento nacional. No caso do Rio de Janeiro, por sua vez, a razão de chance foi bem menor, alcançando apenas $14 \%$ em relação a São Paulo. Ou seja, em Santa Catarina o peso do financiamento nacional foi maior, mas os candidatos paulistas obtivem maior atenção dos 
diretórios nacionais do que os cariocas. Já em se tratando do financiamento partidário estadual, os candidatos paulistas tiveram maior suporte financeiro de suas legendas, considerando todos os outros casos selecionados.

\section{Considerações Finais}

Uma preocupação recorrente dos analistas é o distanciamento entre partidos e sociedade. Como as doações privadas de indivíduos expressam o engajamento do cidadão no processo eleitoral, ${ }^{9}$ a sua relevância quase residual no financiamento político é um sintoma da dependência financeira empresarial e pública pela qual os partidos passam. Ou seja, o quadro eleitoral de 2014 era demarcado pela pequena contribuição de pessoas físicas à receita partidária de um lado, e de outro, pelo maior empoderamento financeiro dos partidos, via financiamento público e empresarial.

A partir desse cenário, o artigo buscou discutir como o financiamento partidário realmente importa no processo eleitoral. Neste sentido, vimos o quanto é fundamental para os candidatos a deputado federal obter recursos partidários, principalmente nos maiores distritos eleitorais. O estado de Rondônia, considerando os casos selecionados, foi o que apresentou menor proporção do financiamento partidário sobre a receita dos candidatos. E mesmo assim, esse peso representou quase trinta por cento da arrecadação.

A segunda questão dizia respeito aos maiores beneficiários do financiamento partidário. Vimos que os candidatos com elevado capital político atraíram mais recursos dos partidos. Aliás, dependendo do partido, a discrepância entre a distribuição do dinheiro partidário e a de outras fontes foi bem evidente. Por exemplo, PSDB e PMDB destinaram mais recursos a candidatos com elevado capital político em comparação ao investimento empresarial. ${ }^{10}$

O último ponto visa compreender uma possível lógica distributiva especializada entre as instâncias partidárias. Chegamos à conclusão de que há diferenças significativas

\footnotetext{
${ }^{9}$ Speck (2010) traduziu bem esta perspectiva ao discutir a distribuição de vouchers aos eleitores, que poderiam direcioná-los a candidatos de sua preferência.

${ }^{10}$ Esta interpretação coaduna-se com os achados de Santos (2014), em relação às eleições de 2010 para deputado federal no Rio de Janeiro, nos quais o autor verificou uma tendência maior das empresas financiarem candidatos desafiantes em comparação ao financiamento partidário.
} 
entre diretórios nacionais e subnacionais quanto aos critérios estabelecidos para ajudar financeiramente as candidaturas. Pudemos mapear tais clivagens em aspectos políticoinstitucionais e socioeconômicos.

Quanto aos aspectos político-institucionais, primeiro ficou clara uma divisão de tarefas em termos de capital político. Candidatos com desempenho eleitoral reconhecido e influentes na arena legislativa nacional tiveram maior probabilidade de serem financiados nacionalmente. Já para os diretórios estaduais, estas características tiveram pouco efeito sobre suas decisões de investimento, pesando mais a lealdade partidária dos candidatos.

Em segundo lugar, quanto ao financiamento empresarial obtido pelos candidatos, verificamos que elites empresariais e elites partidárias nacionais acabaram por financiar os mesmos candidatos. Políticos importantes para os partidos nacionalmente atraem recursos de grandes doadores de campanha. Esta associação não ocorre quando observado o repasse partidário subnacional.

Por último, vimos que a coalizão subnacional importa apenas para a decisão de financiamento dos diretórios estaduais. Entretanto, ser forte eleitoralmente no estado atrai a atenção dos diretórios nacionais. Aqui a lógica nacional se dá mais estritamente em função de votos e possibilidade de maximizar cadeiras no estado, do que necessariamente em razão de acordos políticos subnacionais.

Os candidatos, lançados por partidos efetivos na Câmara dos Deputados, tendem a ter maior financiamento partidário nacional do que subnacional. Esta tendência ficou ainda mais forte no caso de candidaturas petistas. Demonstrando que, apesar de o PT ser retratado na literatura como um partido mais inclusivo pelo selectorate, a autoridade partidária nacional busca influenciar na arena eleitoral escolhendo candidatos nos estados para financiá-los.

Quanto aos aspectos socioeconômicos, em termos comparativos, ficou mais evidente que a característica profissional importou mais para diretórios subnacionais. Há aqui uma divisão de tarefas. Nacionalmente, cremos que a profissão exerça menor impacto, pois o que importaria seria a profissionalização da carreira política demarcada pela sua trajetória dentro da organização partidária. Indicando que a predisposição 
profissional à política teria maior efeito sobre estágios iniciais da carreira política, que predominantemente fica a encargo das instâncias subnacionais.

Considerando este argumento, o fato de as mulheres receberem menos recursos partidários nacionais se daria em decorrência da consolidação da carreira política dos candidatos que no estágio inicial pouco abrem espaço para as mulheres. Confirmando a importância de se atentar para uma abordagem mais precisa, quanto ao gênero, dos processos de recrutamento partidário.

Em resumo, consideramos que o artigo contraditou boa parte de uma produção acadêmica notabilizada por não identificar a importância estratégica das organizações partidárias na arena eleitoral. De maneira prospectiva, uma vez que novas regras eleitorais (fim do financiamento empresarial) se estabelecem, torna-se pertinente observar que o cálculo dos atores é redefinido. $\mathrm{O}$ debate proposto no artigo cumpre o papel de observar a lógica partidária de financiamento de campanhas, visando também compreender possíveis cenários eleitorais futuros, nos quais o dinheiro partidário será ainda mais proeminente no processo eleitoral.

\section{Referências}

ÁLVARES, M.L. Formação de elites \& seleção de candidaturas: o "jardim secreto" da elaboração das listas partidárias. In: ENCONTRO ANUAL DA ANPOCS, 31., 2007, Caxambu. Anais [...]. Caxambu: ANPOCS, 2007. Disponível em: https://anpocs.com/index.php/encontros/papers/31-encontro-anual-da-anpocs/st-7/st16-5 /2928-mariaalvares-formacao/file. Acesso em: 22/12/2019.

AMES, B. Electoral strategy under open-list proportional representation. American Journal of Political Science, v. 39, n. 2, p. 406-33, 1995.

BRAGA. M. S. S. Organizações partidárias e seleção de candidatos no estado de São Paulo. Opinião Pública, Campinas, v. 14, n. 2, p. 454-485, 2008.

BRAGA, M., VEIGA, L., MIRÍADE, A. Recrutamento e perfil dos candidatos e dos eleitos à Câmara dos Deputados nas eleições de 2006. Revista Brasileira de Ciências Sociais, São Paulo, v.24, n.70, p.123-142, 2009.

CERVI, E. U. (2011), O uso do HGPE como recurso partidário em eleições proporcionais no Brasil: um instrumento de análise de conteúdo. Opinião Pública, Campinas, v. 17, n. 1, p. 106-136, 2011. 
CODATO, A; COSTA, L. D.; MASSIMO, L. Classificando ocupações prévias à entrada na política: uma discussão metodológica e um teste empírico. Opinião Pública, Campinas, v. 20, n. 3, p. 346-362, 2014.

DUVERGER, M. Os partidos políticos. Rio de Janeiro: Zahar/UnB, 1980.

FIGUEIREDO, A. C.; LIMONGI, F. Executivo e legislativo na nova ordem constitucional. 2. ed. Rio de Janeiro: Editora Fundação Getúlio Vargas, 2001.

FIGUEIREDO FILHO, D.B. O elo corporativo? Grupos de interesse, financiamento de campanha e regulação eleitoral. 2009. Dissertação (Mestrado em Ciência Política) - Programa de Pós-Graduação em Ciência Política, Universidade Federal de Pernambuco, Recife, 2009.

FREIDENBERG, F. e LOPES, F. S. Como se escolhe um candidato a Presidente? Regras e práticas nos partidos políticos da América Latina. Opinião Púbica, Campinas, v. 8, n. 2, p. 158-88, 2008.

GALLAGHER, M.; MARSH, M. Candidate selection in comparative perspective: the secret garden of politics. London: Sage, 1988.

GUARNIERI, F. Partidos, seleção de candidatos e comportamento político. 2004. Dissertação (Mestrado em Ciência Política) - Faculdade de Filosofia, Letras e Ciências Humanas, Universidade de São Paulo, São Paulo, 2004.

HAZAN, R. Candidate selection. In: LEDUC, L.; NIEMI, R.G; NORRIS, P. (Eds.). Comparing democracies 2: new challenges in the study of elections and voting. London: Sage Publications, 2002, p. 108-126.

KATZ, R.; MAIR, P. Changing models of party organization and party democracy: the emergence of the cartel party". Party Politics, London, v. 1, n. 1, p. 5-28, 1995.

LAAKSO, M.; TAAGEPERA, R. Effective number of parties: a measure with application to West Europe. Comparative Political Studies, v. 12, n. 1, p.3-27, 1979.

MAINWARING, S. A democracia presidencialista multipartidária: o caso Brasil. Lua Nova, São Paulo, n. 28/29, p. 21-74, 1993.

MAINWARING, S. Sistemas partidários em novas democracias: o caso do Brasil. Rio de Janeiro: Editora Fundação Getúlio Vargas, 2001.

MAINWARING, S.; O’DONNEL, G.; VENEZUELA, S. J. Issues in democratic consolidation: the new south american democracies in comparative perspective. Notre Dame: University of Notre Dame Press, 1992.

MANCUSO W. P. Investimento eleitoral no Brasil: balanço da literatura e agenda de pesquisa. Revista de Sociologia e Política, Curitiba, v. 23, n. 54, p. 155-183, 2015. 
MARCELINO, D. Sobre dinheiro e eleições: um estudo dos gastos de campanha para o Congresso Nacional em 2002 e 2006. 2010. Dissertação (Mestrado em Ciência Política) - Programa de Pós-Graduação em Ciência Política, Universidade de Brasília, Brasília, 2010.

NEVES, A. C. Geografia do voto e conexão eleitoral nas eleições de 1994 a 2006 para deputado federal no Piaú. 2010. Dissertação (Mestrado em Ciência Política) Programa de Pós-Graduação em Ciência Política, Universidade Federal do Piauí, Piauí, 2010.

NICOLAU, J. O sistema eleitoral de lista aberta no Brasil. Dados, Rio de Janeiro, v. 49, n. 4, p. 689-720, 2006.

PANEBIANCO, A. Modelos de partido: organização e poder nos partidos políticos. São Paulo: Martins Fontes, 2005.

RAHAT, G.; HAZAN, R. Y. Candidate selection methods an analytical framework. Political Studies, v. 7, n.3 p. 297-322, 2001.

RUBIO, D.F. Financiamento de partidos e campanhas: fundos públicos vs. fundos privados. Novos Estudos Cebrap, São Paulo, n. 73, p. 6-16, 2005.

SACCHET, T.; SPECK, B. Financiamento eleitoral, representação política e gênero: uma análise das eleições de 2006. Opinião Pública, Campinas, v.18, n. 1, p. 177-197, 2012.

SAMUELS, D. Determinantes do voto partidário em sistemas eleitorais centrados no candidato: evidências sobre o Brasil. Dados, Rio de Janeiro, v. 40, n. 3, 1997.

SANDES-FREITAS, V. E. V. de. Alianças partidárias nos estados brasileiros: das coligações às coalizões de governo (1986-2010). 2015. Tese (Doutorado em Ciência Política) - Programa de Pós-Graduação em Ciência Política, Universidade Estadual de Campinas, Campinas, 2015.

SANTOS, Rodrigo D. Partidos na arena eleitoral: o financiamento das listas de candidatos a deputado federal no Rio de Janeiro em 2010. Paraná Eleitoral, Curitiba, v. 3, n. 1, p. 133-169, 2014.

SANTOS, R. D.; TRAVAGIN, L. B. As eleições para prefeito no Rio de Janeiro: uma análise sobre partidos, coligações e a política subnacional. Teoria \& Pesquisa, São Carlos, v. 24, n. 2, p. 121, 2015.

SARTORI, G. Parties and party systems: a framework for analysis. University of Essex: ECPR Press, 2005.

SPECK, B. W. Três ideias para oxigenar o debate sobre dinheiro e política no Brasil. Em Debate, Belo Horizonte, v. 2, n.3, p. 6-13, 2010. 
TAVARES, J. A. G. O problema do cociente partidário na teoria e na prática brasileiras do mandato representativo. Dados, Rio de Janeiro, v. 42, n. 1, p. 63-110, 1999.

VAN BIEZEN, I. Political parties as public utilities. Party Politics, London, v. 10, n. 6, p. 701-722, 2004.

Recebido em: 20/09/2019.

Aceito em: 29/10/2019.

\section{Apêndices}

O banco de dados foi organizado da seguinte forma: as linhas são as doações, ou seja, cada observação significa uma doação recebida pelo candidato; as colunas são as variáveis. Incluímos na base de dados as doações de todas as fontes de financiamento recebidas pelos candidatos a deputado federal. As observações se referem à arrecadação financeira dos candidatos. Como já informado no início do artigo, os estados selecionados foram: SP, RJ, SC, PI e RO.

\subsection{Variáveis do modelo de regressão logística}

Quadro 3 - Características políticas do candidato

\begin{tabular}{|c|c|c|c|c|c|c|c|c|c|c|}
\hline & & & & Do & o Par & ria & & & & \\
\hline Variável & Modelo & Descrição & Não & $\%$ & Sim & $\%$ & Total & $\begin{array}{c}\text { Cramer's } \\
\mathrm{V}\end{array}$ & $\begin{array}{c}\text { Pearson } \\
\text { Chi- } \\
\text { Square }\end{array}$ & $\begin{array}{c}\text { Approx. } \\
\text { Sig. }\end{array}$ \\
\hline & & Capital Constante & 5464 & 0,41 & 7788 & 0,59 & 13252 & 0,4152 & $9075,257 a$ & 0,000 \\
\hline & & Capital Antigo & 1464 & 0,46 & 1731 & 0,54 & 3195 & & & \\
\hline & IVlod-A & Capital Novo & 5356 & 0,71 & 2135 & 0,29 & 7491 & & & \\
\hline & & Sem Capital & 24362 & 0,85 & 4341 & 0,15 & 28703 & & & \\
\hline Capital & & Total & 36646 & 0,70 & 15995 & 0,30 & 52641 & & & \\
\hline Político & & Capital Constante & 1505 & 0,11 & 11747 & 0,89 & 13252 & 0,1217 & $780,084 a$ & 0,000 \\
\hline & & Capital Antigo & 369 & 0,12 & 2826 & 0,88 & 3195 & & & \\
\hline & $\begin{array}{l}\text { Mod-B } \\
\text { (SubNacional) }\end{array}$ & Capital Novo & 934 & 0,12 & 6557 & 0,88 & 7491 & & & \\
\hline & & Sem Capital & 5976 & 0,21 & 22727 & 0,79 & 28703 & & & \\
\hline & & Total & 8784 & 0,17 & 43857 & 0,83 & 52641 & & & \\
\hline & & non DIAP & 35748 & 0,75 & 12231 & 0,25 & 47979 & 0,3413 & $6130,985 a$ & 0,000 \\
\hline & (Nacion-A & DIAP & 898 & 0,19 & 3764 & 0,81 & 4662 & & & \\
\hline 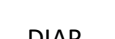 & & Total & 36646 & 0,70 & 15995 & 0,30 & 52641 & & & \\
\hline Diar & & non DIAP & 8442 & 0,18 & 39537 & 0,82 & 47979 & 0,0782 & $321,700 a$ & 0,000 \\
\hline & (SubNacional) & DIAP & 342 & 0,07 & 4320 & 0,93 & 4662 & & & \\
\hline & & Total & 8784 & 0,17 & 43857 & 0,83 & 52641 & & & \\
\hline Lealdade & & Partido diferente & 2359 & 0,75 & 775 & 0,25 & 3134 & 0,2155 & $918,538 a$ & 0,000 \\
\hline
\end{tabular}


DOLANDELI, Rodrigo dos; TANAKA, Marcela. A. O financiamento partidário e a estratégia de doações na arena eleitoral. Caos - Revista Eletrônica de Ciências Sociais, João Pessoa, n. 23, p. 197 - 232, jul./dez. 2019. Disponível em: https://periodicos.ufpb.br/ojs2/index.php/caos/index.

\begin{tabular}{|c|c|c|c|c|c|c|c|c|c|}
\hline \multirow{2}{*}{$\begin{array}{c}\text { Mod-A } \\
\text { (Nacional) }\end{array}$} & Mesmo Partido & 7620 & 0,46 & 9030 & 0,54 & 16650 & & & \\
\hline & Total & 9979 & 0,50 & 9805 & 0,50 & 19784 & & & \\
\hline \multirow{3}{*}{$\begin{array}{c}\text { Mod-B } \\
\text { (SubNacional) }\end{array}$} & Partido diferente & 482 & 0,15 & 2652 & 0,85 & 3134 & 0,0141 & $3,933 a$ & 0,047 \\
\hline & Mesmo Partido & 2336 & 0,14 & 14314 & 0,86 & 16650 & & & \\
\hline & Total & 2818 & 0,14 & 16966 & 0,86 & 19784 & & & \\
\hline
\end{tabular}

\section{- Capital Político}

Esta variável foi criada com base na combinação do desempenho eleitoral de duas campanhas: 2010 e 2014. É uma variável categórica ordinal.

\section{- DIAP (dummy)}

Esta é uma variável dummy que indica se o candidato, entre 2011 e 2014, foi apontado ou não pelo Departamento Intersindical de Assessoria Parlamentar (DIAP) como "cabeça" do Congresso em pelo menos um ano. O DIAP é reconhecido por realizar uma publicação de grande relevância no meio político, que lista os protagonistas do processo decisório nacional. O objetivo da variável é estabelecer uma proxy da relevância política do candidato na arena legislativa.

\section{- Lealdade (dummy)}

Esta variável é uma dummy, que mostra se o candidato participou ou não na eleição anterior pelo mesmo partido que concorreu em 2014. O objetivo é demonstrar se o político não migrou de partido, indicando assim lealdade à legenda.

Quadro 4 - Características socioeconômicas do candidato

\begin{tabular}{|c|c|c|c|c|c|c|c|c|c|c|}
\hline & & & $\begin{array}{l}\text { Doação } \\
\text { Partidária }\end{array}$ & & & & Esta & sticas & & \\
\hline Variável & Modelo & Descrição & Não & $\%$ & Sim & $\%$ & Total & $\begin{array}{c}\text { Cramer's } \\
\mathrm{V}\end{array}$ & $\begin{array}{l}\text { Pearson } \\
\text { Chi- } \\
\text { Square }\end{array}$ & $\begin{array}{l}\text { Approx. } \\
\text { Sig. }\end{array}$ \\
\hline \multirow{6}{*}{ Gênero } & \multirow{3}{*}{$\begin{array}{c}\text { Mod-A } \\
\text { (Nacional) }\end{array}$} & Masculino & 30479 & 0,69 & 13694 & 0,31 & 44173 & 0,0306 & $49,225 a$ & 0,000 \\
\hline & & Feminino & 6167 & 0,73 & 2301 & 0,27 & 8468 & & & \\
\hline & & Total & 36646 & 0,70 & 15995 & 0,30 & 52641 & & & \\
\hline & \multirow{3}{*}{$\begin{array}{c}\text { Mod-B } \\
\text { (SubNacional) }\end{array}$} & Masculino & 7484 & 0,17 & 36689 & 0,83 & 44173 & 0,0157 & $12,931 a$ & 0,000 \\
\hline & & Feminino & 1300 & 0,15 & 7168 & 0,85 & 8468 & & & \\
\hline & & Total & 8784 & 0,17 & 43857 & 0,83 & 52641 & & & \\
\hline \multirow{6}{*}{$\begin{array}{l}\text { Disposição } \\
\text { Política } \\
\text { (Profissão) }\end{array}$} & \multirow{3}{*}{$\begin{array}{c}\text { Mod-A } \\
\text { (Nacional) }\end{array}$} & non Alta & 13907 & 0,79 & 3708 & 0,21 & 17615 & 0,1439 & $1090,600 a$ & 0,000 \\
\hline & & Alta & 22739 & 0,65 & 12287 & 0,35 & 35026 & & & \\
\hline & & Total & 36646 & 0,70 & 15995 & 0,30 & 52641 & & & \\
\hline & \multirow{3}{*}{$\begin{array}{c}\text { Mod-B } \\
\text { (SubNacional) }\end{array}$} & non Alta & 3346 & 0,19 & 14269 & 0,81 & 17615 & 0,0439 & $101,488 a$ & 0,000 \\
\hline & & Alta & 5438 & 0,16 & 29588 & 0,84 & 35026 & & & \\
\hline & & Total & 8784 & 0,17 & 43857 & 0,83 & 52641 & & & \\
\hline
\end{tabular}

- Gênero (Masculino e Feminino) 
Dentro da abordagem de trabalhos recentes, que confirmam o menor incentivo às mulheres à política (SACCHET; SPECK, 2012), incluímos essa variável para mensurar as razões de chance de o gênero influenciar o financiamento partidário.

\section{- Disposição para a política (Profissões)}

Esta variável dummy foi construída com base nas características profissionais dos candidatos, inspirando-se na classificação feita por Codato, Costa e Massimo (2014). Originalmente, os autores dividiram as profissões em (a) carreira flexível; (b) status social e (c) afinidade com a atividade política. A profissão que combina estas três características ao mesmo tempo é classificada como tendo uma "Alta Disposição" para a política. São exemplos desta categoria, os profissionais liberais e funcionários públicos. Portanto, esta variável mostra se candidatos têm ou não esta característica profissional de "Alta Disposição" para a política.

Quadro 5 - Características do financiamento político do candidato

\begin{tabular}{|c|c|c|c|c|c|c|c|c|c|c|}
\hline & & & \multicolumn{5}{|c|}{ Doação Partidária } & \multicolumn{3}{|c|}{ Estatísticas } \\
\hline Variável & Modelo & Descrição & Não & $\%$ & $\operatorname{Sim}$ & $\%$ & Total & Cramer's V & $\begin{array}{c}\text { Pearson Chi- } \\
\text { Square }\end{array}$ & $\begin{array}{l}\text { Approx. } \\
\text { Sig. }\end{array}$ \\
\hline \multirow{6}{*}{$\begin{array}{c}\text { Grande } \\
\text { Doador } \\
\text { Empresarial }\end{array}$} & \multirow{3}{*}{$\begin{array}{c}\text { Mod-A } \\
\text { (Nacional) }\end{array}$} & Non NEP & 2910 & 0,61 & 1829 & 0,39 & 4739 & \multirow[t]{3}{*}{0,0790} & \multirow[t]{3}{*}{$30,679 a$} & \multirow[t]{3}{*}{0,000} \\
\hline & & NEP & 70 & 0,40 & 103 & 0,60 & 173 & & & \\
\hline & & Total & 2980 & 0,61 & 1932 & 0,39 & 4912 & & & \\
\hline & \multirow{3}{*}{$\begin{array}{c}\text { Mod-B } \\
\text { (SubNacional) }\end{array}$} & Non NEP & 584 & 0,12 & 4155 & 0,88 & 4739 & \multirow[t]{3}{*}{0,0344} & \multirow[t]{3}{*}{$5,800 a$} & \multirow[t]{3}{*}{0,016} \\
\hline & & NEP & 32 & 0,18 & 141 & 0,82 & 173 & & & \\
\hline & & Total & 616 & 0,13 & 4296 & 0,87 & 4912 & & & \\
\hline
\end{tabular}

\section{- Grande doador empresarial (dummy)}

É uma variável dummy feita com base no volume de dinheiro investido pelas empresas no processo eleitoral. O cálculo foi feito por meio da fórmula de fragmentação partidária (NEP). ${ }^{11}$ Aqui calculamos as empresas financeiramente "efetivas" na campanha e as denominamos de "Grande Doador Empresarial". Portanto, esta variável indica se o candidato recebeu ou não contribuições de firmas que se destacaram no financiamento empresarial

Quadro 6 - Características do partido do candidato

Doação Partidária

${ }^{11} \mathrm{O}$ mesmo cálculo foi realizado para analisar o desempenho eleitoral de candidatos e construir a variável Capital Político. Utilizamos a fórmula de fragmentação partidária $\left(1 / \sum \mathrm{p}_{i}{ }^{2}\right)$ criada por Laakso e Taagepera (1979). 
DOLANDELI, Rodrigo dos; TANAKA, Marcela. A. O financiamento partidário e a estratégia de doações na arena eleitoral. Caos - Revista Eletrônica de Ciências Sociais, João Pessoa, n. 23, p. 197 - 232, jul./dez. 2019. Disponível em: https://periodicos.ufpb.br/ojs2/index.php/caos/index.

\begin{tabular}{|c|c|c|c|c|c|c|c|c|c|c|}
\hline Variável & Modelo & Descrição & Não & $\%$ & Sim & $\%$ & Total & $\begin{array}{c}\text { Cramer's } \\
\mathrm{V}\end{array}$ & $\begin{array}{c}\text { Pearson } \\
\text { Chi-Square }\end{array}$ & $\begin{array}{l}\text { Approx. } \\
\text { Sig. }\end{array}$ \\
\hline \multirow{6}{*}{ PT } & \multirow{3}{*}{$\begin{array}{c}\text { Mod-A } \\
\text { (Nacional) }\end{array}$} & non PT & 31238 & 0,77 & 9569 & 0,23 & 40807 & 0,2764 & $3823,606 a$ & 0,000 \\
\hline & & PT & 4073 & 0,44 & 5167 & 0,56 & 9240 & & & \\
\hline & & Total & 35311 & 0,71 & 14736 & 0,29 & 50047 & & & \\
\hline & \multirow{3}{*}{$\begin{array}{c}\text { Mod-B } \\
\text { (SubNacional) }\end{array}$} & non PT & 7379 & 0,18 & 33428 & 0,82 & 40807 & 0,0571 & $163,384 a$ & 0,000 \\
\hline & & PT & 1159 & 0,13 & 8081 & 0,87 & 9240 & & & \\
\hline & & Total & 8538 & 0,17 & 41509 & 0,83 & 50047 & & & \\
\hline \multirow{6}{*}{$\begin{array}{l}\text { Partido } \\
\text { Efetivo }\end{array}$} & \multirow{3}{*}{$\begin{array}{c}\text { Mod-A } \\
\text { (Nacional) }\end{array}$} & Non NEP & 12180 & 0,83 & 2538 & 0,17 & 14718 & 0,2108 & $2002,096 a$ & 0,000 \\
\hline & & NEP & 18782 & 0,62 & 11552 & 0,38 & 30334 & & & \\
\hline & & Total & 30962 & 0,69 & 14090 & 0,31 & 45052 & & & \\
\hline & \multirow{3}{*}{$\begin{array}{c}\text { Mod-B } \\
\text { (SubNacional) }\end{array}$} & Non NEP & 3885 & 0,26 & 10833 & 0,74 & 14718 & 0,1519 & $1039,714 a$ & 0,000 \\
\hline & & NEP & 4231 & 0,14 & 26103 & 0,86 & 30334 & & & \\
\hline & & Total & 8116 & 0,18 & 36936 & 0,82 & 45052 & & & \\
\hline \multirow{10}{*}{$\begin{array}{c}\text { Força } \\
\text { Partidária }\end{array}$} & \multirow{5}{*}{$\begin{array}{c}\text { Mod-A } \\
\text { (Nacional) }\end{array}$} & Quartil 1 & 7508 & 0,79 & 1948 & 0,21 & 9456 & 0,3171 & $4107,327 a$ & 0,000 \\
\hline & & Quartil 2 & 7828 & 0,76 & 2432 & 0,24 & 10260 & & & \\
\hline & & Quartil 3 & 8239 & 0,71 & 3309 & 0,29 & 11548 & & & \\
\hline & & Quartil 4 & 3935 & 0,41 & 5660 & 0,59 & 9595 & & & \\
\hline & & Total & 27510 & 0,67 & 13349 & 0,33 & 40859 & & & \\
\hline & \multirow{5}{*}{$\begin{array}{c}\text { Mod-B } \\
\text { (SubNacional) }\end{array}$} & Quartil 1 & 1831 & 0,19 & 7625 & 0,81 & 9456 & 0,1810 & $1338,964 a$ & 0,000 \\
\hline & & Quartil 2 & 1602 & 0,16 & 8658 & 0,84 & 10260 & & & \\
\hline & & Quartil 3 & 3025 & 0,26 & 8523 & 0,74 & 11548 & & & \\
\hline & & Quartil 4 & 703 & 0,07 & 8892 & 0,93 & 9595 & & & \\
\hline & & Total & 7161 & 0,18 & 33698 & 0,82 & 40859 & & & \\
\hline \multirow{6}{*}{ Gorvernismo } & \multirow{3}{*}{$\begin{array}{c}\text { Mod-A } \\
\text { (Nacional) }\end{array}$} & Non & 19909 & 0,69 & 8976 & 0,31 & 28885 & 0,0165 & $14,402 a$ & 0,000 \\
\hline & & Governista & 16737 & 0,70 & 7019 & 0,30 & 23756 & & & \\
\hline & & Total & 36646 & 0,70 & 15995 & 0,30 & 52641 & & & \\
\hline & \multirow{3}{*}{$\begin{array}{c}\text { Mod-B } \\
\text { (SubNacional) }\end{array}$} & Non & 6808 & 0,24 & 22077 & 0,76 & 28885 & 0,2035 & $2181,020 a$ & 0,000 \\
\hline & & Governista & 1976 & 0,08 & 21780 & 0,92 & 23756 & & & \\
\hline & & Total & 8784 & 0,17 & 43857 & 0,83 & 52641 & & & \\
\hline
\end{tabular}

\section{- PT (dummy)}

É uma variável dummy que indica se o candidato pertencia ou não ao Partido dos Trabalhadores. O objetivo é estimar se o PT, reconhecidamente na literatura especializada como um partido bastante organizado em comparação aos demais partidos, apresenta estratégias diferentes de financiamento partidário.

\section{- Partido Efetivo - NEP (dummy)}

É uma variável dummy feita com base no número de cadeira que o partido político obteve na votação para Câmara dos Deputados em 2010. A exemplo das variáveis "Capital Político" e "Grande Doador Empresarial”, o cálculo foi feito por meio da fórmula de fragmentação partidária (NEP) criada por Laakso e Taagepera (1979). Demonstramos nesta variável, portanto, se o partido do candidato foi efetivo na campanha anterior (2010). 


\section{- Força Partidária}

Esta variável calculou a porcentagem de deputados federais eleitos no estado na campanha anterior (2010). Ou seja, indica a força eleitoral partidária para eleger deputados federais no estado. Esta variável, originalmente contínua, foi categorizada em quartis, sendo o quartil 4 aquele que agrega os partidos com maior porcentagem de deputados eleitos em 2010.

\section{- Governismo (dummy)}

É uma variável dummy que mostra se o partido integra ou não a chapa eleitoral majoritária apoiada pelo governador. Dessa forma, buscamos inferir se este partido está alinhado à base governista no estado, considerando a importância da força política do governador nas campanhas subnacionais.

Quadro 7 - Ambiente da competição eleitoral. Casos Selecionados

\begin{tabular}{|c|c|c|c|c|c|c|c|c|c|c|}
\hline \multirow[b]{2}{*}{ Variável } & \multirow[b]{2}{*}{ Modelo } & \multirow[b]{2}{*}{ Descrição } & \multicolumn{5}{|c|}{ Doação Partidária } & \multicolumn{3}{|c|}{ Estatísticas } \\
\hline & & & Não & $\%$ & Sim & $\%$ & Total & Cramer's V & $\begin{array}{c}\text { Pearson } \\
\text { Chi-Square }\end{array}$ & $\begin{array}{l}\text { Approx. } \\
\text { Sig. }\end{array}$ \\
\hline \multirow{12}{*}{ UF } & \multirow{6}{*}{$\begin{array}{c}\text { Mod-A } \\
\text { (Nacional) }\end{array}$} & $\mathrm{PI}$ & 1733 & 0,59 & 1205 & 0,41 & 2938 & 0,2051 & $2214,568 a$ & 0,000 \\
\hline & & RJ & 11582 & 0,85 & 2079 & 0,15 & 13661 & & & \\
\hline & & RO & 1452 & 0,77 & 428 & 0,23 & 1880 & & & \\
\hline & & SC & 1660 & 0,60 & 1091 & 0,40 & 2751 & & & \\
\hline & & SP & 20219 & 0,64 & 11192 & 0,36 & 31411 & & & \\
\hline & & Total & 36646 & 0,70 & 15995 & 0,30 & 52641 & & & \\
\hline & \multirow{6}{*}{$\begin{array}{c}\text { Mod-B } \\
\text { (SubNacional) }\end{array}$} & $\mathrm{PI}$ & 617 & 0,21 & 2321 & 0,79 & 2938 & 0,2037 & $2186,121 \mathrm{a}$ & 0,000 \\
\hline & & RJ & 3472 & 0,25 & 10189 & 0,75 & 13661 & & & \\
\hline & & RO & 615 & 0,33 & 1265 & 0,67 & 1880 & & & \\
\hline & & SC & 656 & 0,24 & 2095 & 0,76 & 2751 & & & \\
\hline & & SP & 3424 & 0,11 & 27987 & 0,89 & 31411 & & & \\
\hline & & Total & 8824 & 0,17 & 43857 & 0,83 & 52681 & & & \\
\hline
\end{tabular}

- UF

Indica a unidade da federação na qual o financiamento de campanha se desenvolveu. Esta variável nos ajudará a identificar a maior razão de chance de o financiamento partidário ocorrer, considerando cada estado selecionado.

\subsection{Modelo completo de regressão logística}

Quadro 8 - Análise multivariada. Regressão logística binomial. (Modelo A Financiamento Partidário Nacional e Modelo B - Financiamento Partidário Subnacional)

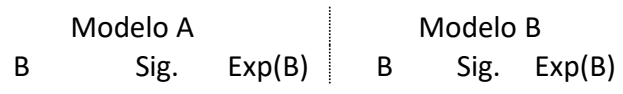


DOLANDELI, Rodrigo dos; TANAKA, Marcela. A. O financiamento partidário e a estratégia de doações na arena eleitoral. Caos - Revista Eletrônica de Ciências Sociais, João Pessoa, n. 23, p. 197 - 232, jul./dez. 2019. Disponível em: https://periodicos.ufpb.br/ojs2/index.php/caos/index.

\begin{tabular}{|c|c|c|c|c|c|c|c|c|}
\hline \multirow{6}{*}{$\begin{array}{l}\text { características } \\
\text { políticas do } \\
\text { candidato }\end{array}$} & \multirow{4}{*}{ Capital Político } & \multirow{3}{*}{$\begin{array}{l}\text { ref.: Sem Capital } \\
\text { Capital Frequente } \\
\text { Capital Antigo }\end{array}$} & \multicolumn{3}{|c|}{,000 } & \multicolumn{3}{|c|}{,000 } \\
\hline & & & 982 & ,000 & 2,670 &,- 848 & ,056 & 428 \\
\hline & & &,- 221 & 380 & ,802 & $-1,613$ & ,000 & 199 \\
\hline & & Capital Novo & 1,153 & ,003 & 3,169 & $-2,597$ & ,000 & ,074 \\
\hline & DIAP & ref.: Cabeça DIAP & 1,103 &, 000 & 3,014 & $-1,380$ & ,000 & ,251 \\
\hline & Lealdade & $\begin{array}{l}\text { ref.: Mesmo Partido } \\
\text { Eleição anterior }\end{array}$ & ,649 & ,001 & 1,913 & 1,586 & ,000 & 4,882 \\
\hline \multirow{3}{*}{$\begin{array}{l}\text { características } \\
\text { socioeconômicas } \\
\text { do candidato }\end{array}$} & & ref.: Feminino & & & & & & \\
\hline & Genero & Masculino & ,701 & ,000 & 2,016 & 100 & ,790 & 1,105 \\
\hline & Dispos Política & ref.: alta disposição & ,104 & ,564 & 1,110 & 1,167 & ,000 & 3,212 \\
\hline $\begin{array}{l}\text { financiamento } \\
\text { empresarial do } \\
\text { candidato }\end{array}$ & $\begin{array}{l}\text { Grande } \\
\text { Doador } \\
\text { Empresarial }\end{array}$ & $\begin{array}{l}\text { ref.: ter recebido } \\
\text { doação de empresas } \\
\text { efetivas } \\
\text { financeiramente } \\
\text { (grandes doadores). }\end{array}$ & 1,316 & ,000 & 3,728 &,- 758 & ,082 & ,468 \\
\hline \multirow{7}{*}{$\begin{array}{l}\text { características do } \\
\text { partido do } \\
\text { candidato }\end{array}$} & Partidos & ref.: PT & 871 & ,007 & 2,390 &,- 827 &, 080 & ,437 \\
\hline & Partido Efetivo & $\begin{array}{l}\text { ref.: Partido Efetivo } \\
\text { na Câmara } \\
\text { Deputados em } 2010\end{array}$ & 1,830 & ,000 & 6,231 & 1,582 & ,000 & 4,863 \\
\hline & & Ref. Quartil 1 & & ,000 & & & ,000 & \\
\hline & Força & Quartil 2 & $-1,088$ & ,000 & ,337 & $-2,569$ & ,000 & ,077 \\
\hline & Partidária & Quartil 3 & 389 & 122 & 1,476 & $-4,605$ & ,000 & ,010 \\
\hline & & Quartil 4 & ,274 & , 406 & 1,315 & $-1,304$ &, 052 & ,271 \\
\hline & Governismo & $\begin{array}{l}\text { ref.: partido } \\
\text { pertencer à coalizão } \\
\text { do governador na UF }\end{array}$ &,- 216 & ,257 & 806 & 1,778 & ,000 & 5,920 \\
\hline \multirow{6}{*}{$\begin{array}{l}\text { ambiente da } \\
\text { competição } \\
\text { eleitoral. Casos } \\
\text { Selecionados }\end{array}$} & & Ref: SP & & ,000 & & & ,000 & \\
\hline & & $\mathrm{PI}$ &,- 146 & ,553 & 864 & ,249 & ,627 & 1,283 \\
\hline & UF & RJ & $-1,755$ & ,000 & 173 &,- 718 & ,116 & ,488 \\
\hline & & RO &,- 101 & ,772 & ,904 & $-3,428$ & ,000 & ,032 \\
\hline & & SC & ,972 & , 000 & 2,643 & $-3,197$ &, 000 & ,041 \\
\hline & & Constant & $-3,475$ & ,000 & ,031 & 3,540 & ,000 & 34,466 \\
\hline -2 Log likelihood & & & \multicolumn{3}{|c|}{ "1854,876a } & \multicolumn{3}{|c|}{ 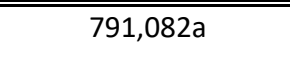 } \\
\hline $\begin{array}{l}\text { Cox \& Snell R } \\
\text { Square }\end{array}$ & & & \multicolumn{3}{|c|}{,359 } & \multicolumn{3}{|c|}{, 284} \\
\hline $\begin{array}{l}\text { Nagelkerke R } \\
\text { Square }\end{array}$ & & & \multicolumn{3}{|c|}{,486 } & \multicolumn{3}{|c|}{, 554} \\
\hline
\end{tabular}

Fonte: Elaborado pelos autores com base em dados do site do TSE. Método Enter.

Mod. A. VD - Candidato recebeu financiamento partidário nacional: Sim (1); Não (0)

Mod. B. VD - Candidato recebeu financiamento partidário subnacional: Sim (1); Não (0) 